NASA Contractor Report 3006

\title{
Horizontal Eddy Diffusivities in the Northern Hemispheric Stratosphere and Lower Mesosphere
}

S. K. Kao, R. J. Okrasinski, and N. J. Lordi

CONTRACT NAS6-2498

JUNE 1978

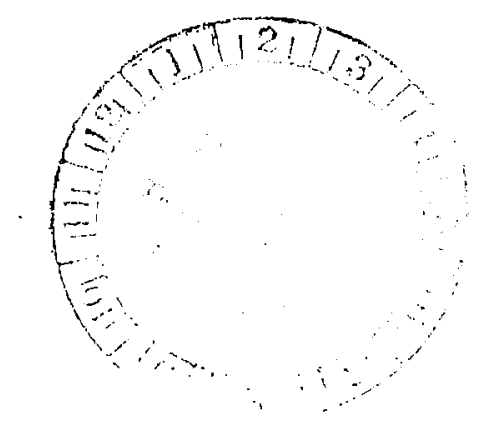




\section{NASA Contractor Report 3006}

\section{Horizontal Eddy Diffusivities in the Northern Hemispheric Stratosphere and Lower Mesosphere}

S. K. Kao, R. J. Okrasinski, and N. J. Lordi

University of Utab

Salt Lake City, Utab

Prepared for

Wallops Flight Center

under Contract NAS6-2498

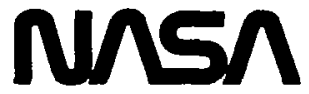

National Aeronautics

and Space Administration

Scientific and Technical

Information Office

1978 


\section{HORIZONTAL EDDY DIFFUSIVITIES IN THE NORTHERN HEMISPHERIC STRATOSPHERE}

\section{AND LOWER MESOSPHERE}

\section{by}

S. K. Kao, R. J. Okrasinski and N. J. Lordi

University of Utah

\section{SUMMARY}

Meteorological rocket soundings, launched between 1969-74 at six locations representative of low, middle, and high altitudes, are employed with the use of the statistical theory of diffusion, to determine the zonal and meridional component of eddy diffusivity between 30 and $55 \mathrm{~km}$ as a function of season, latitude, and altitude. A comparison is also made between annually-averaged eddy diffusivities above and below $30 \mathrm{~km}$.

It is shown that the zonal component of eddy diffusivity is approximately three to five times as large as the meridional component, in most cases. Both components of eddy diffusivity vary greatly with season, latitude, and altitude. Highest eddy diffusivities, found in the vicinity of the winter westerly jet, are approximately one order of magnitude higher than those present during the summer. Tropical eddy diffusivities, however, remain relatively small throughout the year. Annually, a minimum is indicated near $25 \mathrm{~km}$ between maximums located at the stratopause and tropopause. 


\section{Error}

An error occurred while processing this page. See the system log for more details. 
of wind velocity measured between 28 and $57 \mathrm{~km}$ by meteorological rockets launched between 1969-74 at various latitudes. Annual eddy diffusivities are also calculated and compared with eddy diffusivities below $30 \mathrm{~km}$.

\section{THEORETICAL. BACKGROUND}

Statistical theory, first formulated by G. I. Taylor (1921), is used to determine the zonal and meridional components of eddy diffusivity. The turbulent component of wind velocity in the $i$ th direction, $u_{i}(t)$, is assumed to be statistically stationary in which case the autocorrelation function

$$
R_{i}(\tau)=\frac{\left[u_{i}(t) u_{j}(t+\tau)\right]}{\left[u_{i}^{2}(t)\right]},
$$

where

$$
\begin{aligned}
& \mathrm{R}_{j}(\tau) \rightarrow 1 \text { as } \tau \rightarrow 0, \\
& \mathrm{R}_{j}(\tau) \rightarrow 0 \text { as } \tau \rightarrow \infty,
\end{aligned}
$$

is both stationary and even. If the autocorrelation function is integrated between 0 and some $1 \mathrm{ag} t_{L}$, where $R\left(t_{L}\right)$ approaches 0 , the resulting quantity is known as the integral time scale

$$
I_{i}=\int_{0}^{t_{L}} R_{j}(\tau) d \tau .
$$

Taylor (1921) demonstrated that the rate of change of the square of particle distance can be expressed as

$$
\begin{aligned}
\varepsilon_{i}=\frac{1}{2} d \frac{\left[x_{i}{ }^{2}(t)\right]}{d t} & =\frac{1}{2}\left[\frac{d\left(x_{i}^{2}(t)\right)}{d t}\right]=\left[x_{i}(t) \frac{d x_{i}(t)}{d t}\right] \\
& =\left[x_{i}(t) u_{L i}(t)\right],
\end{aligned}
$$

where $U_{L i}$ is the Lagrangian wind velocity, or the velocity of a fluid particle. Since 


$$
\begin{aligned}
& x_{i}(t)=\int_{0}^{t} u_{L i}\left(t^{\prime}\right) d t^{\prime}, \\
& \frac{1}{2} d \frac{\left[x_{j}^{2}(t)\right]}{d t}=\int_{0}^{t}\left[u_{L i}(t) u_{L i}\left(t^{\prime}\right)\right] d t^{\prime} .
\end{aligned}
$$

Integrating both sides with respect to $t$ and letting $t^{\prime}=t-\tau$

$$
\frac{1}{2}\left[x_{i}^{2}(t)\right]=\int_{0}^{t} \int_{0}^{t^{\prime}}\left[u_{L i}\left(t^{\prime}-\tau\right) u_{L i}\left(t^{\prime}\right)\right] d \tau d t^{\prime}
$$

Substituting (1) remembering that $R_{j}(\tau)=R_{j}(-\tau)$

$$
\left[x_{i}^{2}(t)\right]=2\left[u_{i}^{2}(t)\right] \int_{0}^{t} \int_{0}^{t^{\prime}} R_{L i}(\tau) d \tau d t^{\prime} .
$$

Thus the $i$ th component of eddy diffusivity can be expressed as

$$
\varepsilon_{i}(t)=\left[u_{i}^{2}(t)\right] \int_{0}^{t} R_{L i}(\tau) d \tau,
$$

which for large diffusion time $t$ becomes

$$
\varepsilon_{i}(t)=\left[u_{i}^{2}(t)\right] \quad I_{L i}=K_{i i} .
$$

In the atmosphere, however, Eulerian wind velocities, observed at a fixed location, are more frequently measured. Hay and Pasquili (1959) assumed that the Eulerian autocorrelation function could be related to the Lagrangian autocorrelation function by

$$
R_{E i}(\tau)=R_{L i}\left(B_{i} \tau\right)
$$

where

$$
B_{i} \text { is a constant. }
$$


Integrating both sides from 0 to infinity

$$
\begin{aligned}
\int_{0}^{\infty} R_{E i}(\tau) d \tau & =\int_{0}^{\infty} R_{L i}\left(B_{i} \tau\right) d\left(B_{i} \tau\right) \\
& =\frac{1}{B_{i}} \int_{0}^{\infty} R_{L i}(\tau) d \tau,
\end{aligned}
$$

so that

$$
B_{i} I_{E i}=I_{L i}
$$

We can, therefore, determine the zonal and meridional components of eddy diffusivity by

$$
\begin{aligned}
& k_{x x}=\left[u^{2}(t)\right] B_{u} I_{E u} \\
& k_{y y}=\left[v^{2}(t)\right] B_{v} I_{E v}
\end{aligned}
$$

For the case of large-scale turbulence, Kao and Bullock (1964) and Murgatroyd (1969) have found $B_{i}$ to be between .3 and .6 for heights ranging up to the lower stratosphere. However, since upper stratospheric and mesospheric dynamics are inherently different from tropospheric motions, it would be expected that $B_{i}$ values should differ. In this study $B_{i}$ values were found using the following relationship (Kao, 1965):

$$
B_{i}=\left|\frac{c}{\bar{u}-c}\right| \text {, }
$$

where $C$ represents the phase speed of the dominant wave at a particular altitude and $\bar{u}$ is the value of the mean zonal wind.

For the winter and fall seasons, values of $C$ at levels up to $55 \mathrm{~km}$ were obtained with the use of joint NASA and NOAA high atmosphere synoptic analyses for 1972 (NASA SP-3091, 1975). Due to the relative flatness of 
pressure patterns in the spring and summer the above synoptic analyses could not be used; however, Muench (1968) analyzed summertime balloon ascents in order to determine the existence of a dominant 12 day traveling planetary wave for latitudes from $20-50^{\circ} \mathrm{N}$ ranging between $25-45 \mathrm{~km}$. This information, together with a knowledge of the mean zonal winds, yield a $B_{j}$ of about $1 / 3$ for both stratosphere and lower mesosphere. The wintertime stratosphere is dominated by vertically propagating quasi-stationary waves leading to very small phase speed and hence small $B_{i}$. Using phase speeds determined from the upper atmospheric synoptic analyses, it was determined that $B_{i}$ ranged between .56 at $30 \mathrm{~km}$ and .12 at $55 \mathrm{~km}$ in winter and between .33 at $30 \mathrm{~km}$ and .08 at $55 \mathrm{~km}$ in fall. Values used in this study are given in Table 35.

\section{METHODS OF COMPUTATION}

Rocketsonde Data

Zonal and meridional wind velocities, in one kilometer increments between 28 and $57 \mathrm{~km}$, were obtained from rocketsondes launched between 1969-74 in the Western Meridional Network. NASA Wallops Island, Virginia, supplied the necessary data. Although rocketsonde launchings are often scheduled every two of three days, there are occasionally much larger gaps between observations. On the other hand, some launchings are one day apart or less. In order to analyze latitudinal cross-sections of the Northern Hemisphere, the following ten stations were selected:

1. Poker Flats, Alaska $\left(65^{\circ} \mathrm{N}, 148^{\circ} \mathrm{W}\right)$

2. Ft. Greely, Alaska $\left(64^{\circ} \mathrm{N}, 146^{\circ} \mathrm{W}\right)$

3. Ft. Churchi17, Canada $\left(59^{\circ} \mathrm{N}, 94^{\circ} \mathrm{W}\right)$

4. Wallops Island, Virginia $\left(38^{\circ} \mathrm{N}, 75^{\circ} \mathrm{W}\right)$

5. Pt. Mugu, California $\left(34^{\circ} \mathrm{N}, 119^{\circ} \mathrm{W}\right)$

6. White Sands, New Mexico $\left(32^{\circ} \mathrm{N}, 106^{\circ} \mathrm{W}\right)$

7. Cape Kennedy, Florida $\left(28^{\circ} \mathrm{N}, 81^{\circ} \mathrm{W}\right)$

8. Barking Sands, Hawaij $\left(22^{\circ} \mathrm{N}, 160^{\circ} \mathrm{W}\right)$

9. Ft. Sherman, Panama $\left(9^{\circ} \mathrm{N}, 80^{\circ} \mathrm{W}\right)$

10. Kwajalein, Marshall Islands ( $\left.{ }^{\circ} \mathrm{N}, 168^{\circ} \mathrm{W}\right)$ 
Because of large gaps existing at some of the above locations, the following stations close in latitude were combined:

1. Ft. Greely, Poker Flats, Ft. Churchill

2. Pt. Mugu, White Sands

3. Kwajalein, Ft. Sherman

Wind velocities were, therefore, available for six latitudes.

The sparsity of the rocket network prevented any consideration of longitudinal variations. It should also be noted that eight of the ten stations are located in North America so that during the winter and fall the quantities computed and illustrated in this study are more representative of that continent than they are of the Northern Hemisphere in general. During spring and summer, the flow is almost symmetric around the pole due to the trapping of vertically propagating planetary waves by the mean easterly flow (Charney and Drazin, 1961).

For the purposes of this study, the data were divided into the following four seasons: winter (January-March); spring (April-June); summer (July-September); and fall (October-December). For each six-year period, the number of launch days available in each season ranged from 110 - 160 at Wallops Island to 290 at some of the combined locations. Since most rocketsondes are launched near local noon, fluctuations due to the diurnal oscillation were easily avoided. First, for each station, all soundings launched several hours outside of the estimated mean launch time were visually edited. For each altitude, al1 rocketsonde data from the same day were then averaged. Finally, for each year, season, and station a mean launch time was calculated, and all data not acquired within three hours of this quantity were rejected.

Instrument errors in the above data were reduced by performing a three point vertical smoothing at $55,50,45,40,35$, and $30 \mathrm{~km}$. Next, gross errors were eliminated by removing a linear trend for each year, season, station, and altitude, and then rejecting all velocities greater than 2.3 multiplied by the standard deviation. Finally, from the edited data, the mean zonal and meridional wind velocities were calculated and linear trends were again removed, in order to obtain the turbulent fluctuations necessary to compute the variances and autocorrelations. 
Since six-year autocorrelation functions were desired,

$$
\begin{aligned}
& R_{u}(\tau)=\left(\sum_{i=1}^{N(\tau)} u_{i}(t) u_{i}(t+\tau) /\left(N(\tau) \sigma_{u}{ }^{2}\right)\right. \\
& R_{v}(\tau)=\left(\sum_{i=1}^{N(\tau)} v_{i}(t) v_{i}(t+\tau) /\left(N(\tau) \sigma_{v}{ }^{2}\right)\right.
\end{aligned}
$$

were calculated for each season, station, and latitude; where $u(t)$ and $v(t)$ are tine zonal and meridional wind perturbations, $\tau$ is the 1 ag time, $N(\tau)$ is the total number of soundings, $\tau$ days apart, during the six-year period, and $\sigma_{u}{ }^{2}$ and $\sigma_{v}{ }^{2}$ are the total six-year zonal and meridional variances. $R_{U}(0)$ and $R_{v}(0)$ were assumed to be 1 . In this manner, years with more wind measurements were given more weight in the calculations. Although autocorrelations were calculated for all lags between 1 and 40 days whenever $N(\tau)$ was greater than 34 , most values of $N(\tau)$ ranged between $80-140$ for $\tau$ less than 10 days.

The Eulerian integral time scales were obtained by integrating the autocorrelation functions with respect to $\tau$. After linear regressions with altitude were computed at each station, the smoothed integral time scales were multiplied by the variances and the Lagrangian transformation $B_{i}$, in order to obtain the zonal and meridional components of eddy diffusivity.

Six-year seasonal means, variances, Eulerian integral time scales and eddy diffusivities in the zonal and meridional direction are tabulated in Tables 1-35 and analyzed in Figures 1-34.

\section{Radiosonde Data}

For the sake of comparison, it was desirable to calculate some eddy diffusivities for the troposphere and lower stratosphere. Integral 
time scales were readily available from Kao and Gain (1968) and Kao and Powe11 (1969), who computed the annual Lagrangian autocorrelation functions from the surface to $32 \mathrm{~km}$ at $47^{\circ} \mathrm{N}$. Fortunately, the integral time scales vary with latitude much less than the variances. The latter, computed from standard deviations calculated from radiosondes launched between Ju7y 1957 - December 1964, and tabuTated by Newe11 and others (1972), were available in $10^{\circ}$ increments between $0^{\circ} \mathrm{N}$ and $70^{\circ} \mathrm{N}$.

Eddy diffusivities, calculated with this data, were then combined with the annual mean diffusivities previously computed above $30 \mathrm{~km}$, to obtain the latitudinal cross sections shown in Figures 33 and 34 .

\section{DISCUSSION OF THE RESULTS}

$$
\text { E-W Mean }
$$

The dominance of the westerlies, between August and Apri1, and the easterlies, during the spring and summer, are clearly shown in Figures 1-4. Maximum easterly winds are somewhat weaker and are located at a lower latitude than the maximum winter westerlies. In Figures 1 and 4 , some indication of the semi-annual oscillation is seen near the equatorial stratopause, where the annual wave amplitude is close to zero according to Belmont et al. (1973).

\section{N-S Mean}

As shown in Figures 5-8, the meridional component of mean wind velocity is approximately one-fifth as strong as the zonal wind. Again, a seasonal variation exists, with weaker winds in evidence during the spring and summer. Both seasons are characterized both by two weak maximums of southerly flow located in the lower mesosphere near $45^{\circ} \mathrm{N}$ and $20^{\circ} \mathrm{N}$ and extremely weak flow below $45 \mathrm{~km}$. In contrast, winter and fall are dominated by relatively strong northerlies in the middle stratospheric polar regions and strong southerly flow in the lower mesospheric middle latitudes. 


\section{E-W Variance}

Zonal variances are analyzed in Figures 9-12, in order to obtain some estimate of the average zonal eddy intensity. A much more marked seasonal, latitudinal, and altitudinal dependence is evident, with an order of magnitude difference separating the variances in the middle and high latitude westerlies from those in the summer easterlies. Below $25^{\circ} \mathrm{N}$, however, the difference between winter and spring diminishes with decreasing latitude until no seasonal variation is evident south of $10^{\circ} \mathrm{N}$. The lowest variances are also found in this region, generally below $35 \mathrm{~km}$. Spring and summer are characterized by both an absence of latitudinal variation and a positive correlation of variance with altitude. In contrast, winter and fall are marked by large latitudinal changes; with maximum variances located in the vicinity of the winter westerly jet. The fall latitude-height section differs somewhat from the winter illustration, however, due to the lower variances evident below $45 \mathrm{~km}$ and to the presence of a second strong maximum near the subtropical stratopause.

\section{N-S Variance}

Latitudinal cross sections of the meridional variances are analyzed in Figures 13-16. Although less than one-half the magnitude of the zonal variances, they change similarly with season, latitude, and altitude. A lack of seasonal variation is again indicated for the tropical regions; while the more northern latitudes are characterized by an order of magnitude difference between summer and winter. Variances in the middle stratospheric equatorial regions are again smal1. During spring and summer, a gradual increase with altitude is also characteristic of the meridional variances. Large latitudinal variations are again indicated for winter and fal1, but, in the latter season, the maximum is located in the polar mesosphere instead of at the mid-latitude stratopause.

\section{E-W Integral Time Scale}

The zonal Eulerian integral time scales, illustrated by Figures 17-20, exhibit a much smaller variation with season, latitude, and altitude than the variances. In the tropics, both a lack of seasonal 
variability and short integral time scales are characteristic. The longest time scales in the middle and high latitudes are present during the summer and fall when they are approximately twice as long as those found during the rest of the year. Maximums are located in the midlatitude stratosphere during the winter, spring, and summer; at the midlatitude stratopause in summer and fall; and above $45 \mathrm{~km}$ in the subtropics during winter and fall.

\section{$\mathrm{N}$-S Integral Time Scale}

The meridional Eulerian integral time scales, illustrated in Figures 21-24, are apparently only one-third to one-fifth as long as their zonal counterparts. Again, the shortest time scales are found near the equator and, again, seasonal variation is lacking in this region. In this case, however, the longest integral time scales occur during the winter and fall. Maximums are evident in the middle latitudes below $45 \mathrm{~km}$, during the summer, fal1, and winter; in the subtropics above $50 \mathrm{~km}$, in the spring, summer, and fall; and in the polar middle stratosphere during spring.

\section{E-W Eddy Diffusivity}

A strong seasonal, Tatitudinal, and altitudinal variation of the zonal component of eddy diffusivity is apparent in Figures 25-28. The smallest diffusion rates occur in the equatorial regions, where a lack of seasonal variation is evident. Seasonally, in the more northern latitudes, the smallest eddy diffusivities occur during the spring, with somewhat higher diffusion rates expected in the summer, and much more rapid diffusion indicated for the fall and winter. Two strong diffusivity maxima are characteristic of the latter two seasons, as well as strong diffusivity gradients for these seasons between $20^{\circ} \mathrm{N}$ and $30^{\circ} \mathrm{N}$ at al1 levels. The strong wintertime maximum occurs around $38^{\circ} \mathrm{N}$ at $35 \mathrm{~km}$, while separate fall maxima are evident around $30^{\circ} \mathrm{N}$ at about $33 \mathrm{~km}$ and $50 \mathrm{~km}$. Much weaker gradients prevail in spring and summer at most leveis; however, a noticeable increase in eddy diffusivity in summer occurs above 
$40 \mathrm{~km}$ at $50^{\circ} \mathrm{N}$. The prevailing factor in the determination of the wintertime eddy diffusivity maximum appears to be the general increase in the variance in this region.

\section{N-S Eddy Diffusivity}

Many similarities between the latitude-altitude sections of the meridional component of eddy diffusivity analyzed in Figures 29-32 and the four previous illustrations are obvious. Again, both an order of magnitude difference between the diffusivities in the summer easterlies and winter westerlies and a lack of seasonal variability south of $10^{\circ} \mathrm{N}$ are evident. Altitude and, during the winter and fall, latitude are again important. Summer and spring analyses are similar in distribution and magnitude, with maximum eddy diffusivities occurring above the stratopause. The winter maximum again occurs around $35 \mathrm{~km}$ at $40^{\circ} \mathrm{N}$, and a strong wintertime diffusivity gradient is apparent between $30^{\circ} \mathrm{N}$ and $40^{\circ} \mathrm{N}$ at levels up to $50 \mathrm{~km}$. Fall diffusivities are relatively small below $50^{\circ} \mathrm{N}$; however, north of $50^{\circ} \mathrm{N}$ values increase reaching maximum around $60^{\circ} \mathrm{N}$ between 30 and $35 \mathrm{~km}$. It may be noticed that in a11 cases the meridional component of diffusivity is substantially less than its zonal counterpart. The winter meridional maximum is about one-quarter the zonal maximum, while the summer maximum is an order of magnitude less than its zonal counterpart.

\section{Annual Eddy Diffusivity}

The variation with altitude, and latitude of the mean annual zonal and meridional components of eddy diffusivity is seen in Figures 33 and 34 . Obviously, these illustrations can be discussed simultaneously since the on ty major differences are the more northerly positioning of the meridional maximum and the greater diffusion rates evident in the zonal direction. With respect to the zonal eddy diffusivity component, there is a tropopausal maximum at $40^{\circ} \mathrm{N}$ and a maximum of equal magnitude at $40^{\circ} \mathrm{N}$ at a level of $35 \mathrm{~km}$. Tropical values are 10-20 percent of the mid-1atitude values. The meridional component maximum in the troposphere is about one-half its zonal value, while the stratospheric maximum is about 
one-third its zonal value. The meridional stratospheric maximum shifts northward to $60^{\circ} \mathrm{N}$, while stratospheric values of this component are very small south of $40^{\circ} \mathrm{N}$. 


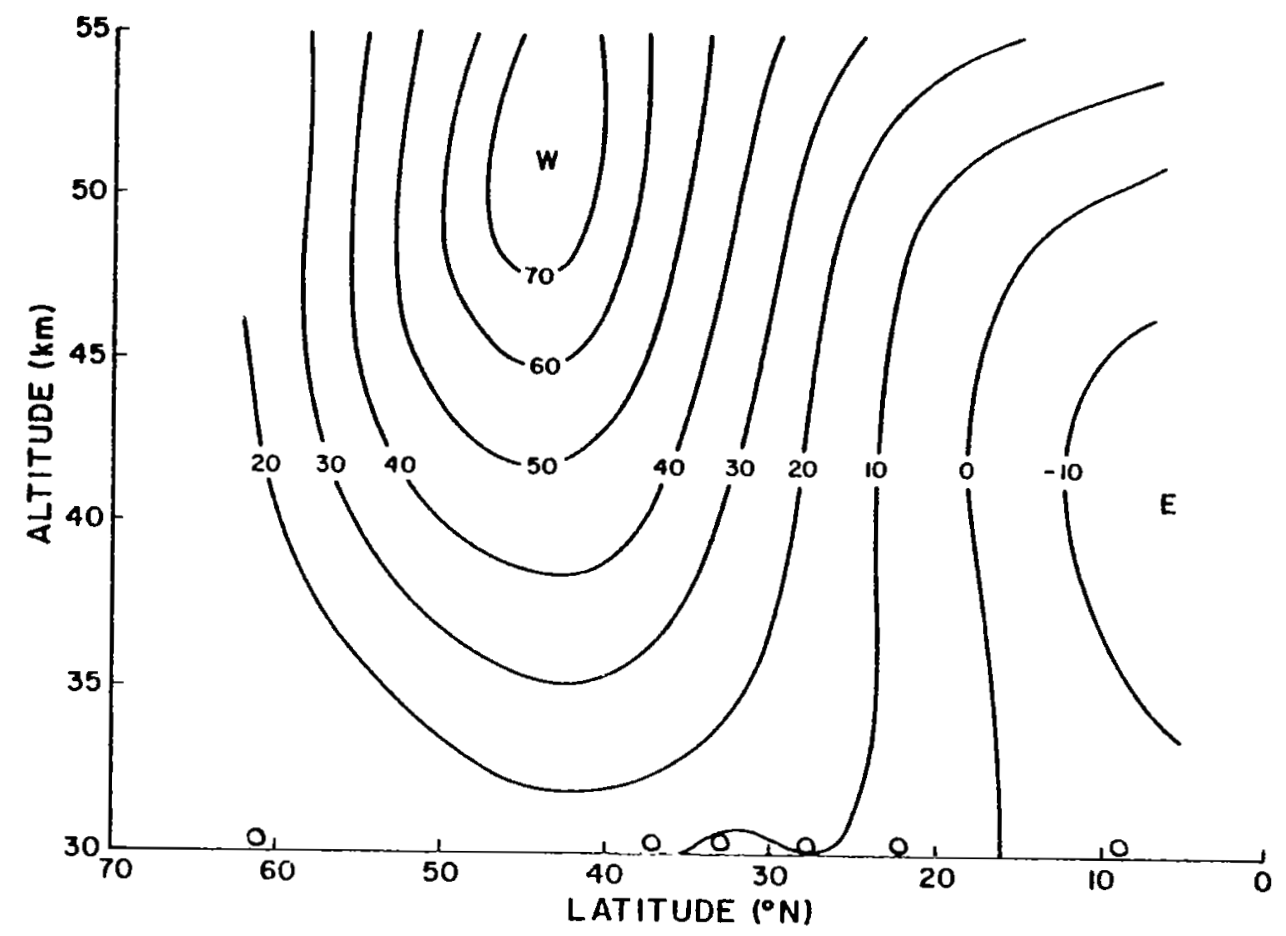

Fig. 1. Latitude-height section of the mean zonal wind (m $\mathrm{sec}^{-1}$ ), Winter 1969-1974. 


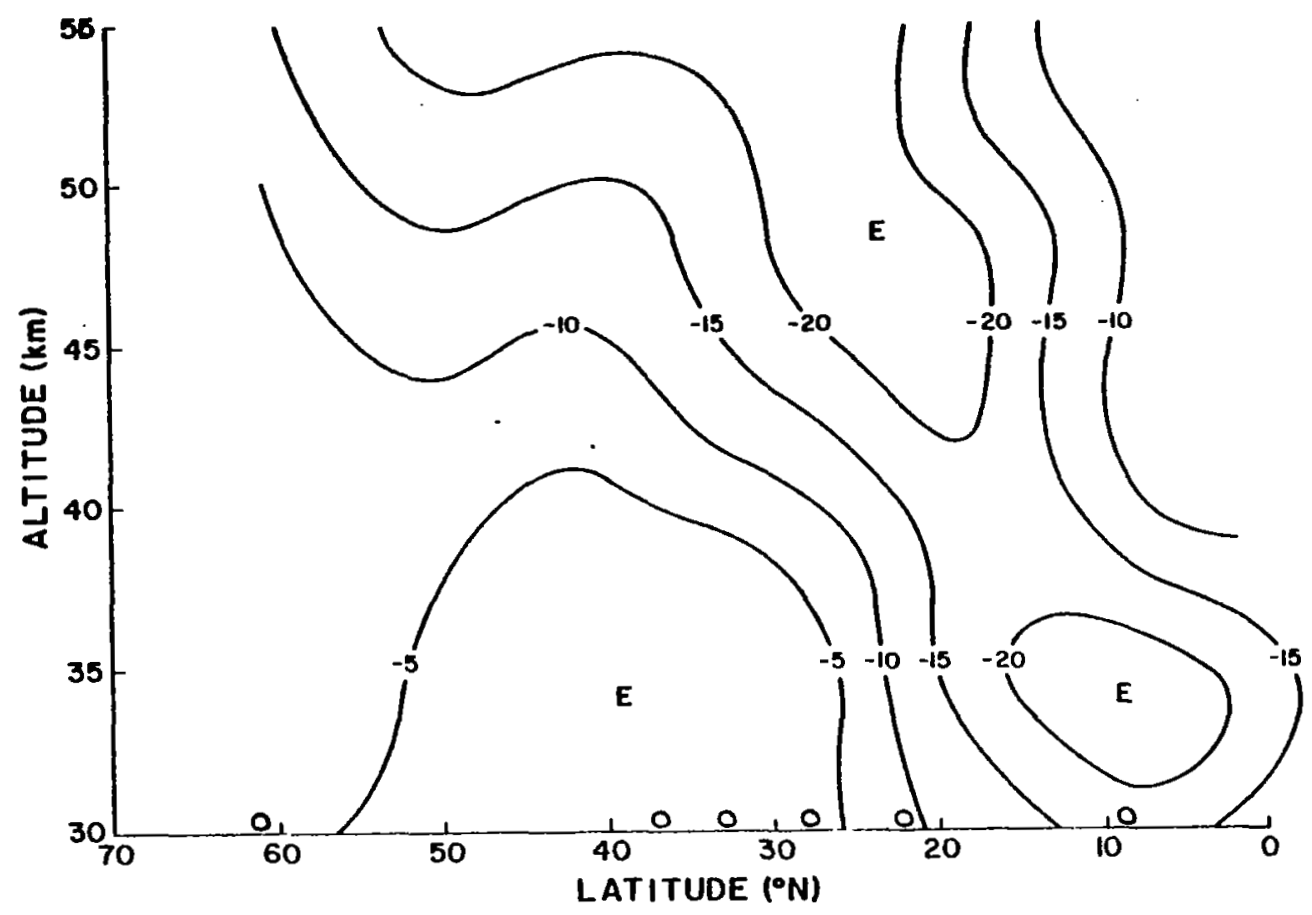

Fig. 2. Latitude-height section of the mean zonal wind ( $\mathrm{sec}^{-1}$ ), Spring 1969-1974. 


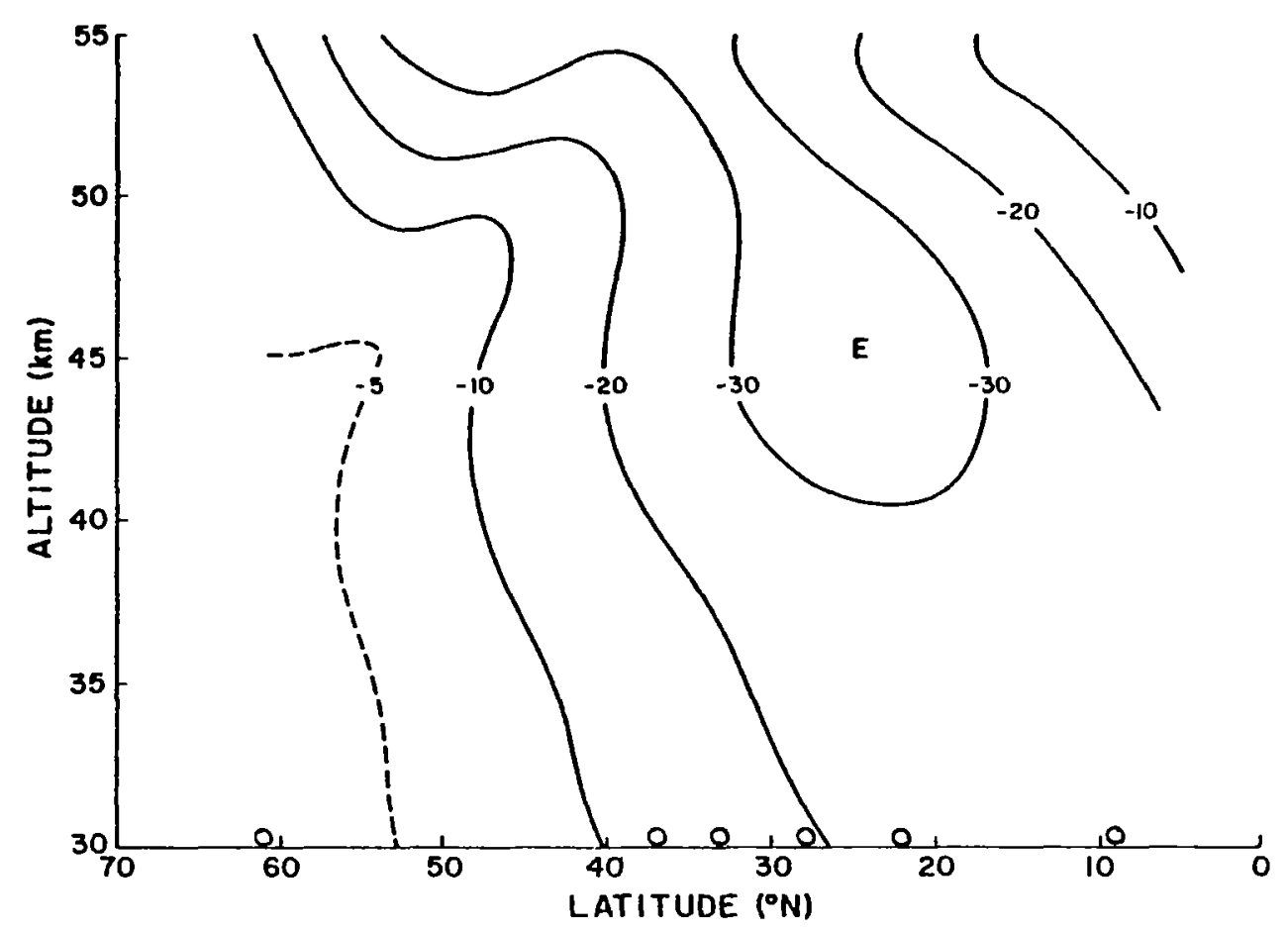

Fig. 3. Latitude-height section of the mean zonal wind ( $m \mathrm{sec}^{-1}$ ), Summer 1969-1974. 


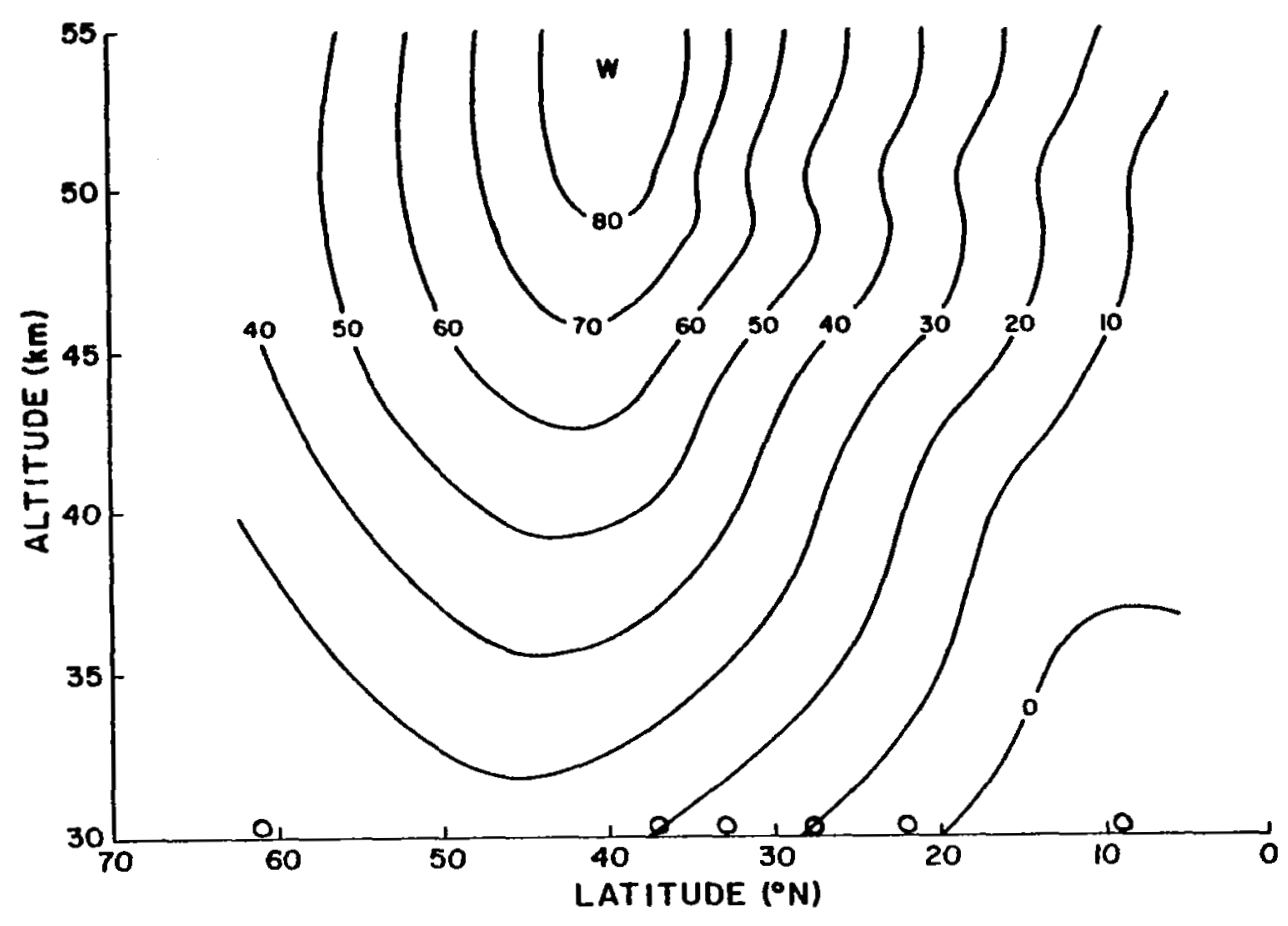

Fig. 4. Latitude-height section of the mean zonal wind ( $m \mathrm{sec}^{-1}$ ), Fal1 1969-1974. 


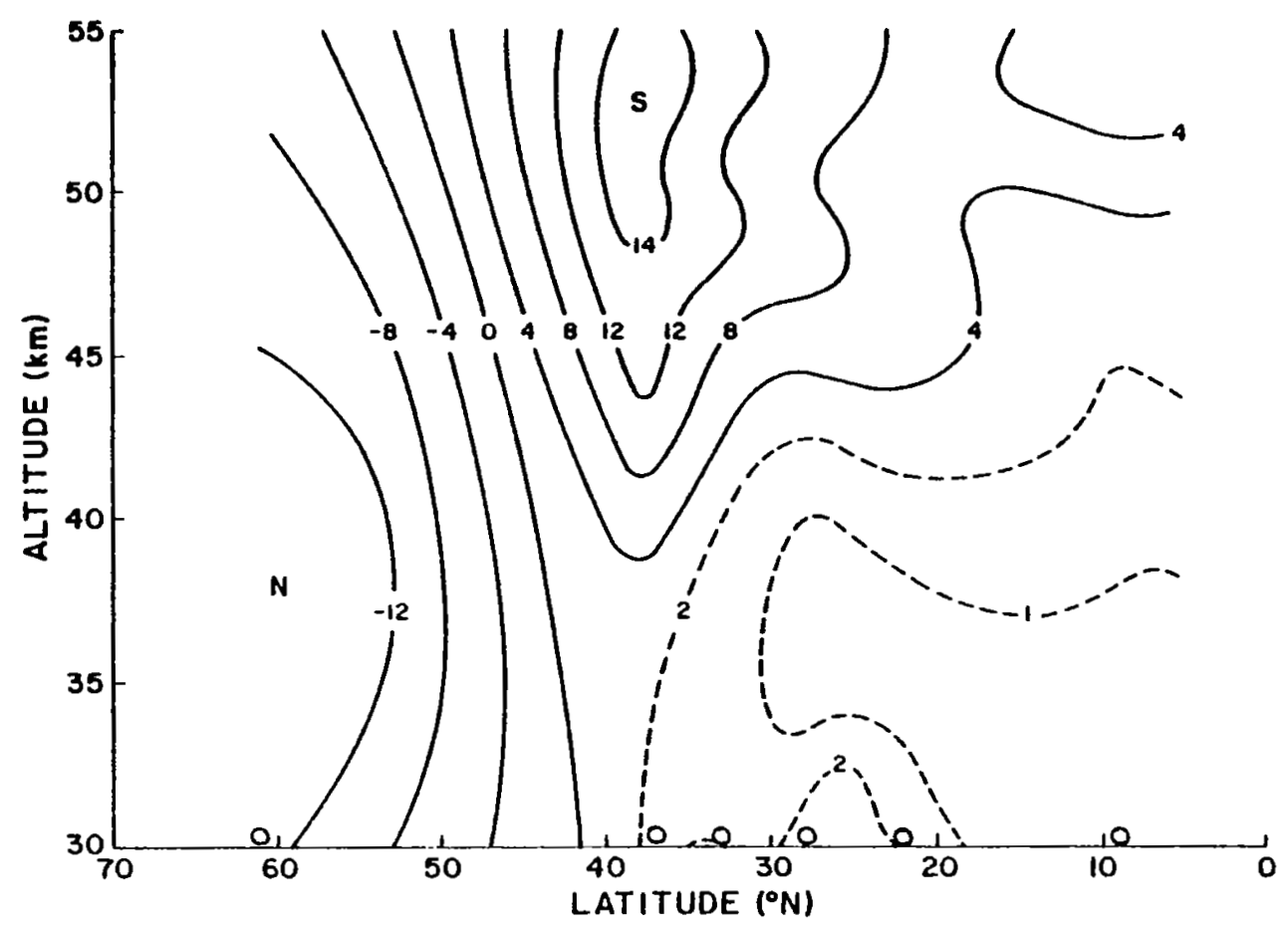

Fig. 5. Latitude-height section of the mean meridional wind (m $\sec ^{-1}$ ), Winter 1969-1974. 


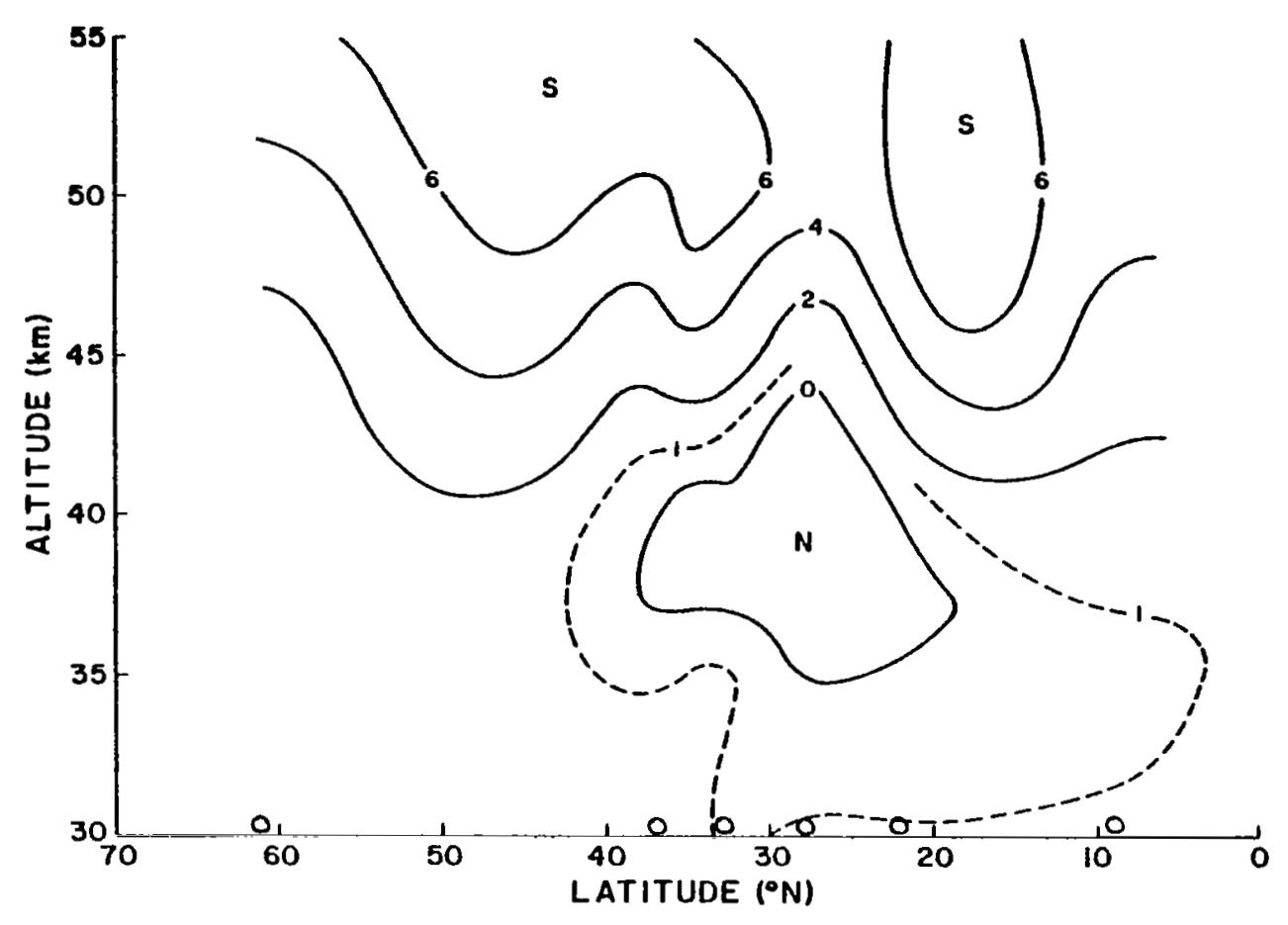

Fig. 6. Latitude-height section of the mean meridional wind (m $\mathrm{sec}^{-1}$ ), Spring 1969-1974. 


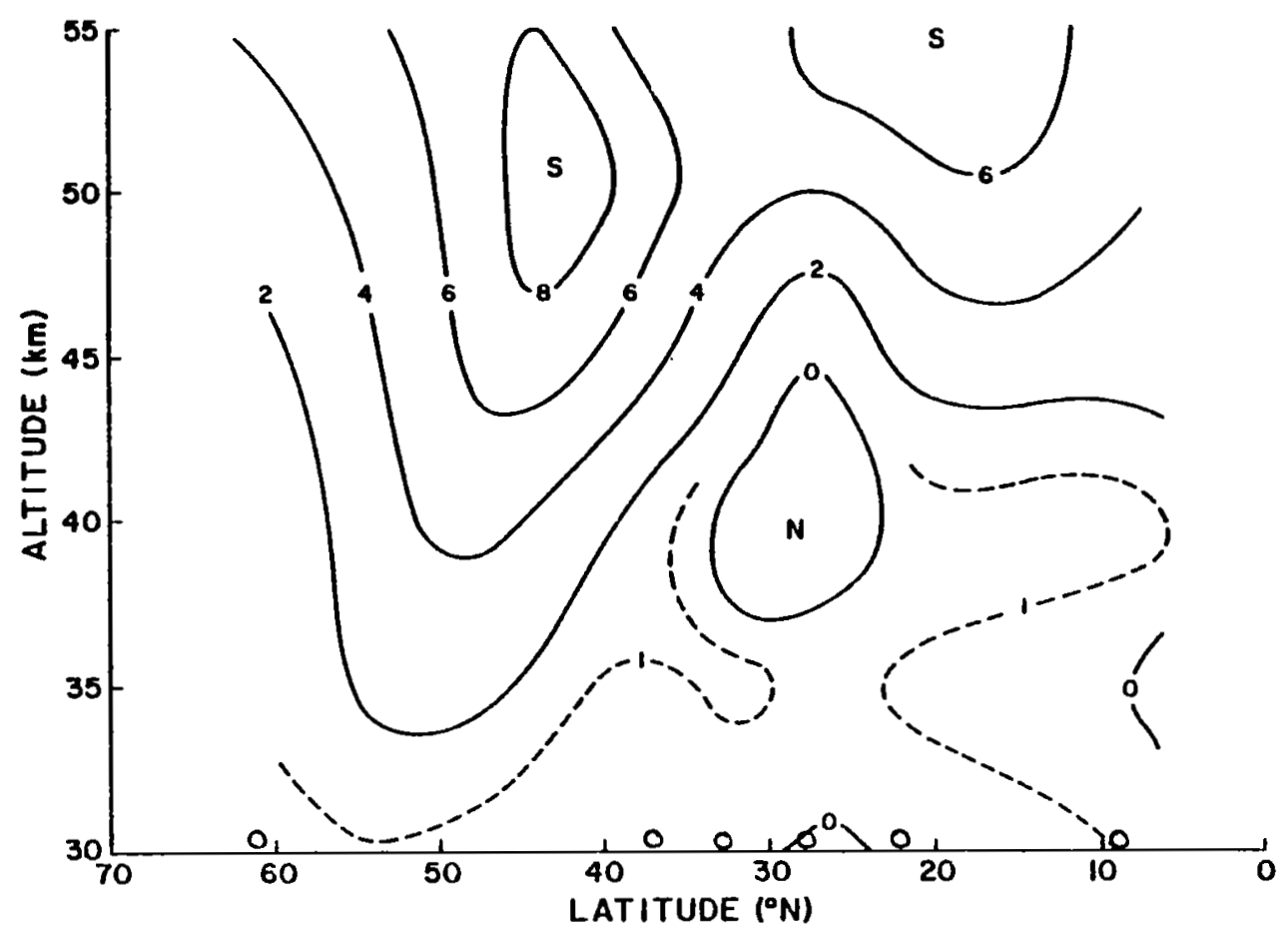

Fig. 7. Latitude-height section of the mean meridonal wind ( $\mathrm{sec}^{-1}$ ), Summer 1969-1974. 


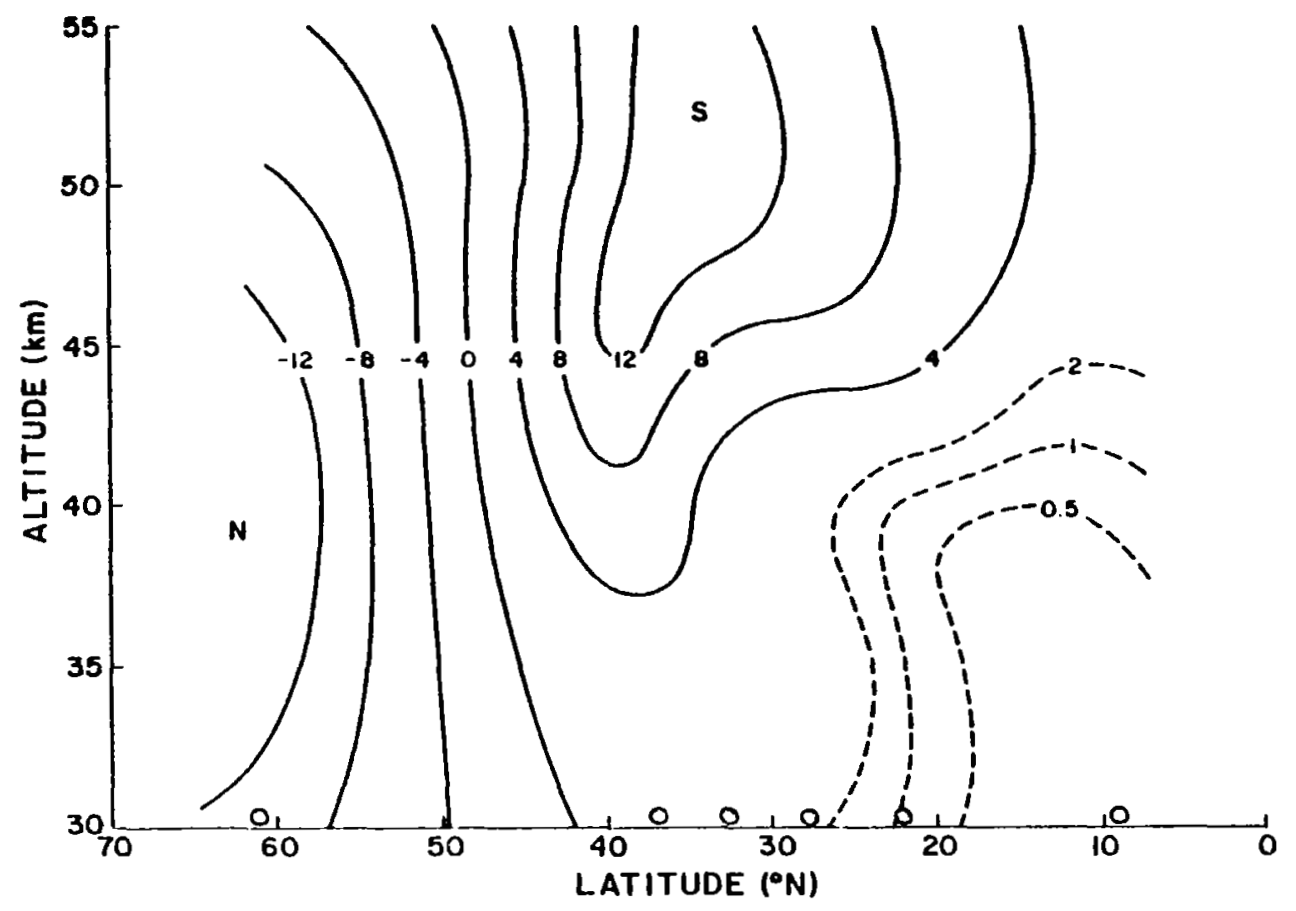

Fig. 8. Latitude-height section of the mean meridional wind (m $\left.\mathrm{sec}^{-1}\right)$, Fall 1969-1974. 


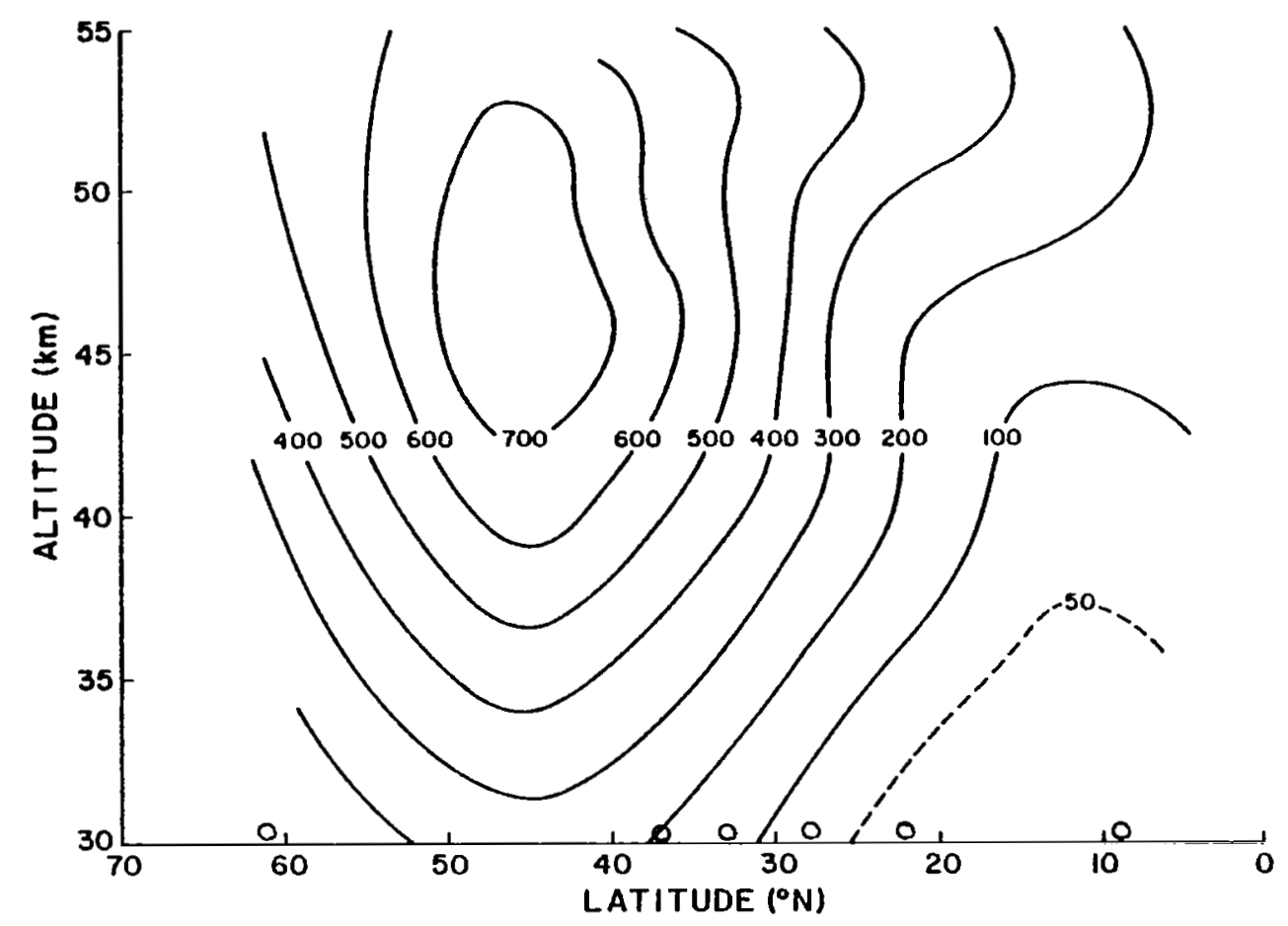

Fig. 9. Latitude-height section of the variance of the zonal wind $\left(\mathrm{m}^{2} \mathrm{sec}^{-2}\right)$, Winter 1969-1974. 


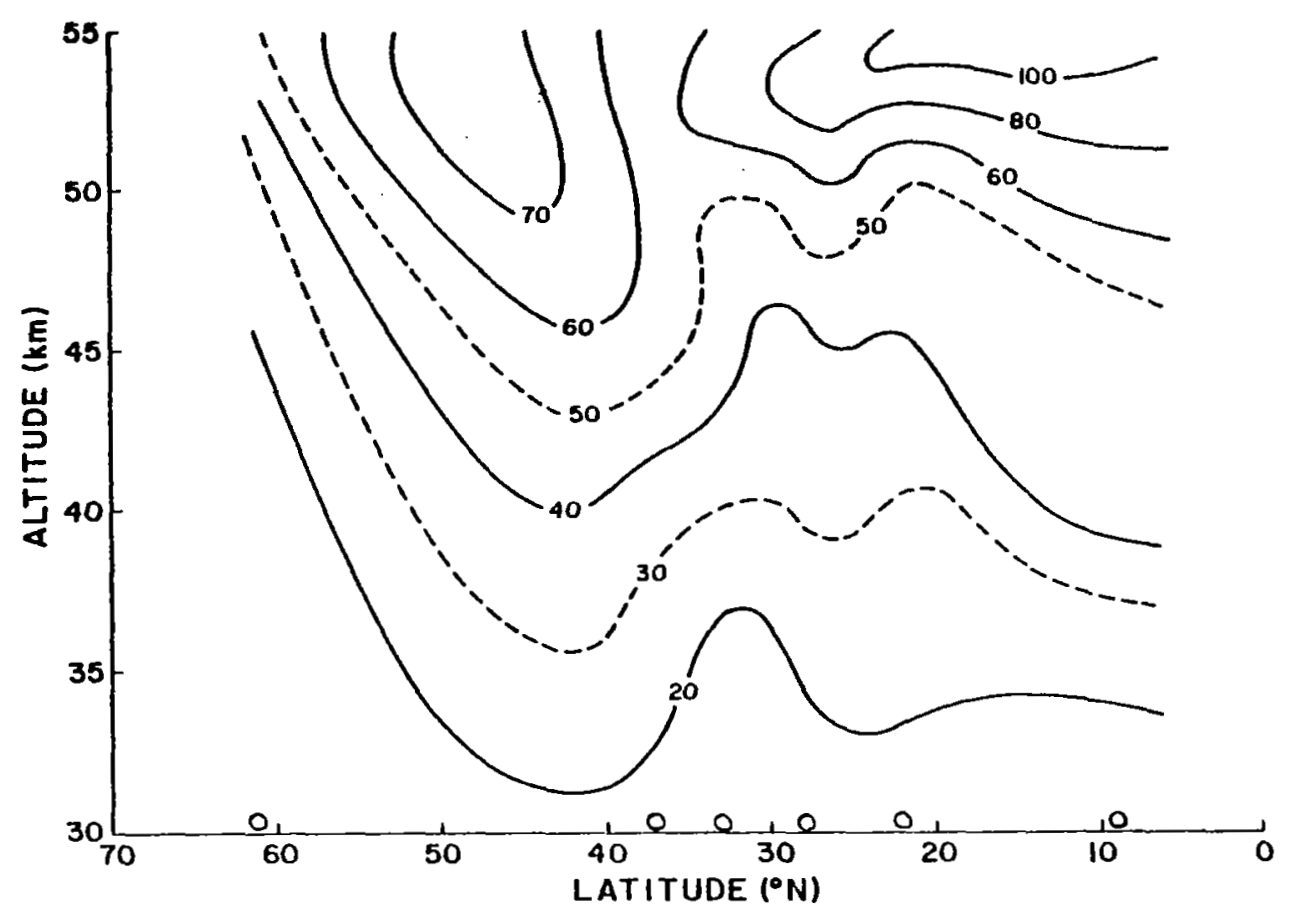

Fig. 10. Latitude-height section of the variance of the zonal wind $\left(\mathrm{m}^{2} \mathrm{sec}^{-2}\right)$, Spring 1969-1974. 


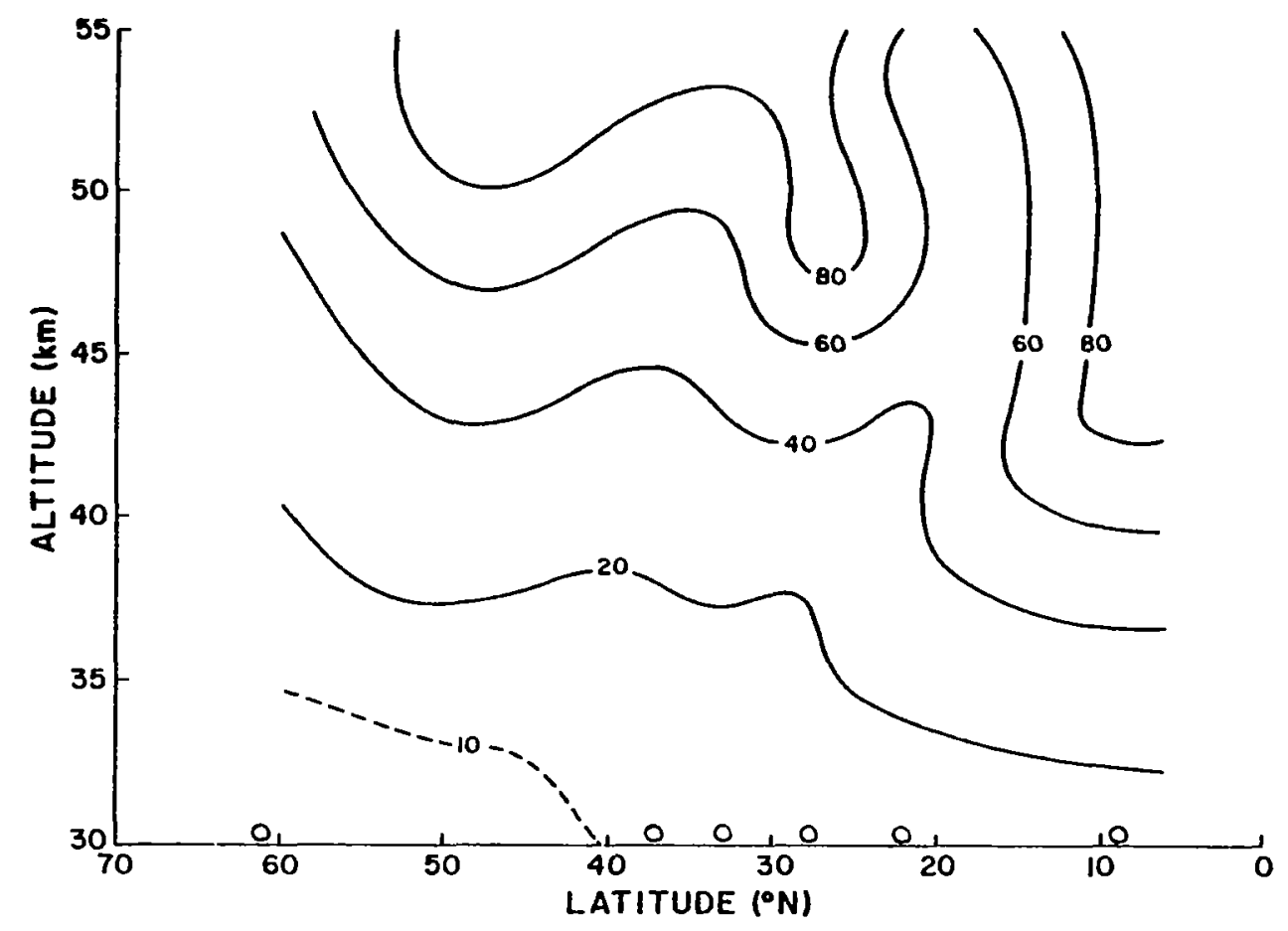

Fig. 11. Latitude-neight section of the variance of the zonal wind $\left(\mathrm{m}^{2} \mathrm{sec}^{-2}\right)$, Summer 1969-1974. 


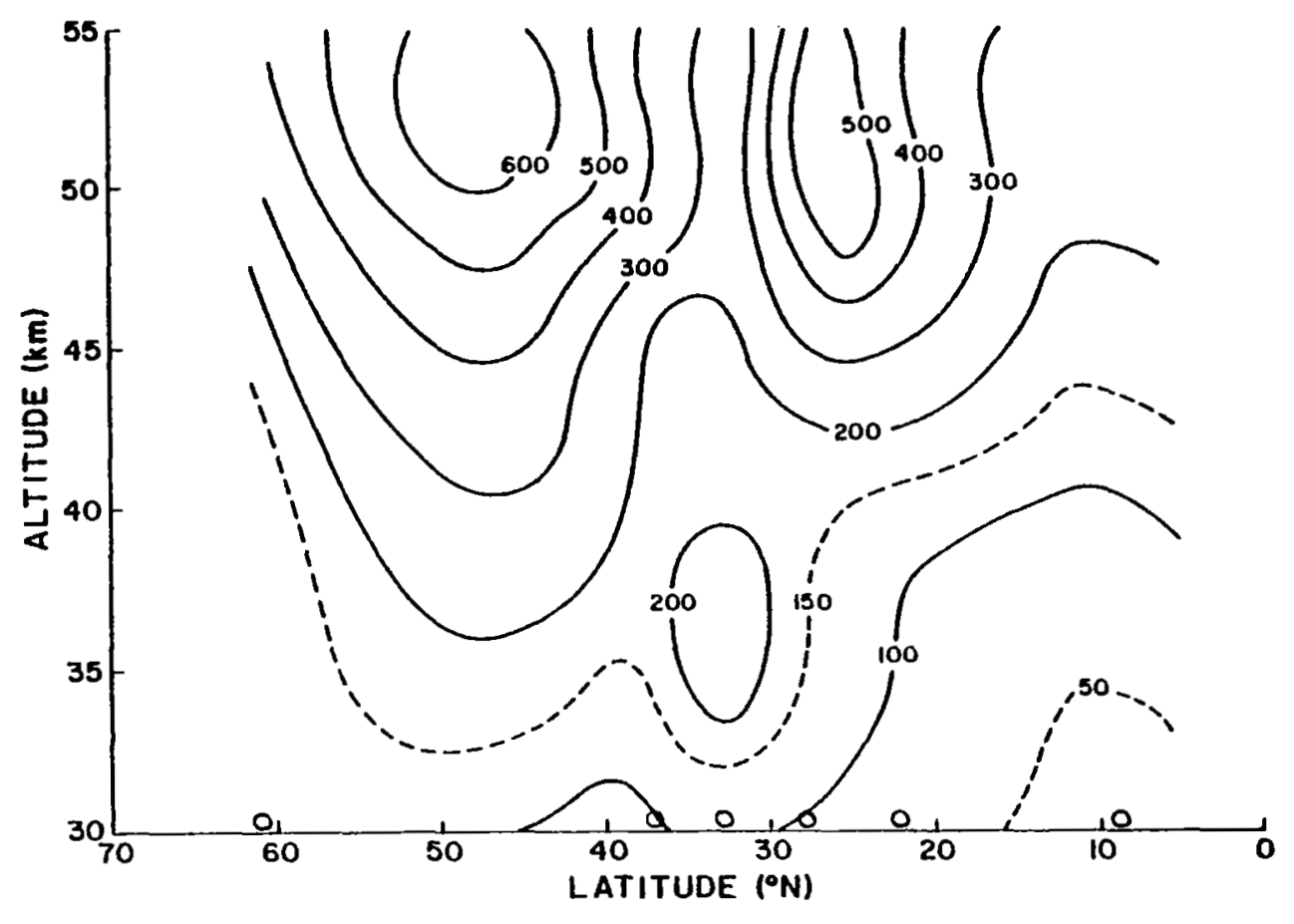

Fig. 12. Latitude-height section of the variance of the zonal wind $\left(\mathrm{m}^{2} \mathrm{sec}^{-2}\right)$, Fall 1969-1974. 


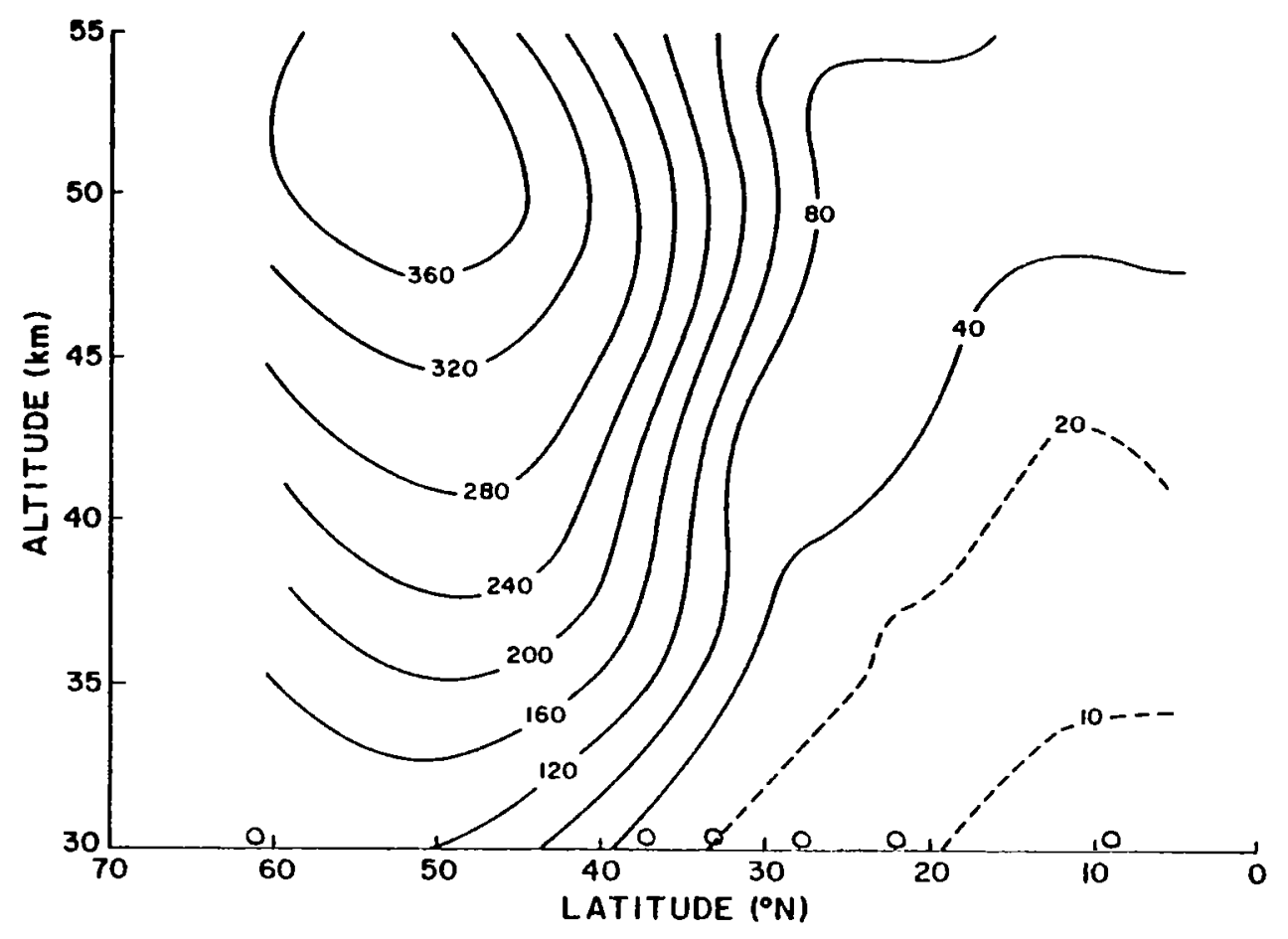

Fig. 13. Latitude-height section of the variance of the meridional wind $\left(\mathrm{m}^{2} \mathrm{sec}^{-2}\right)$, Winter 1969-1974. 


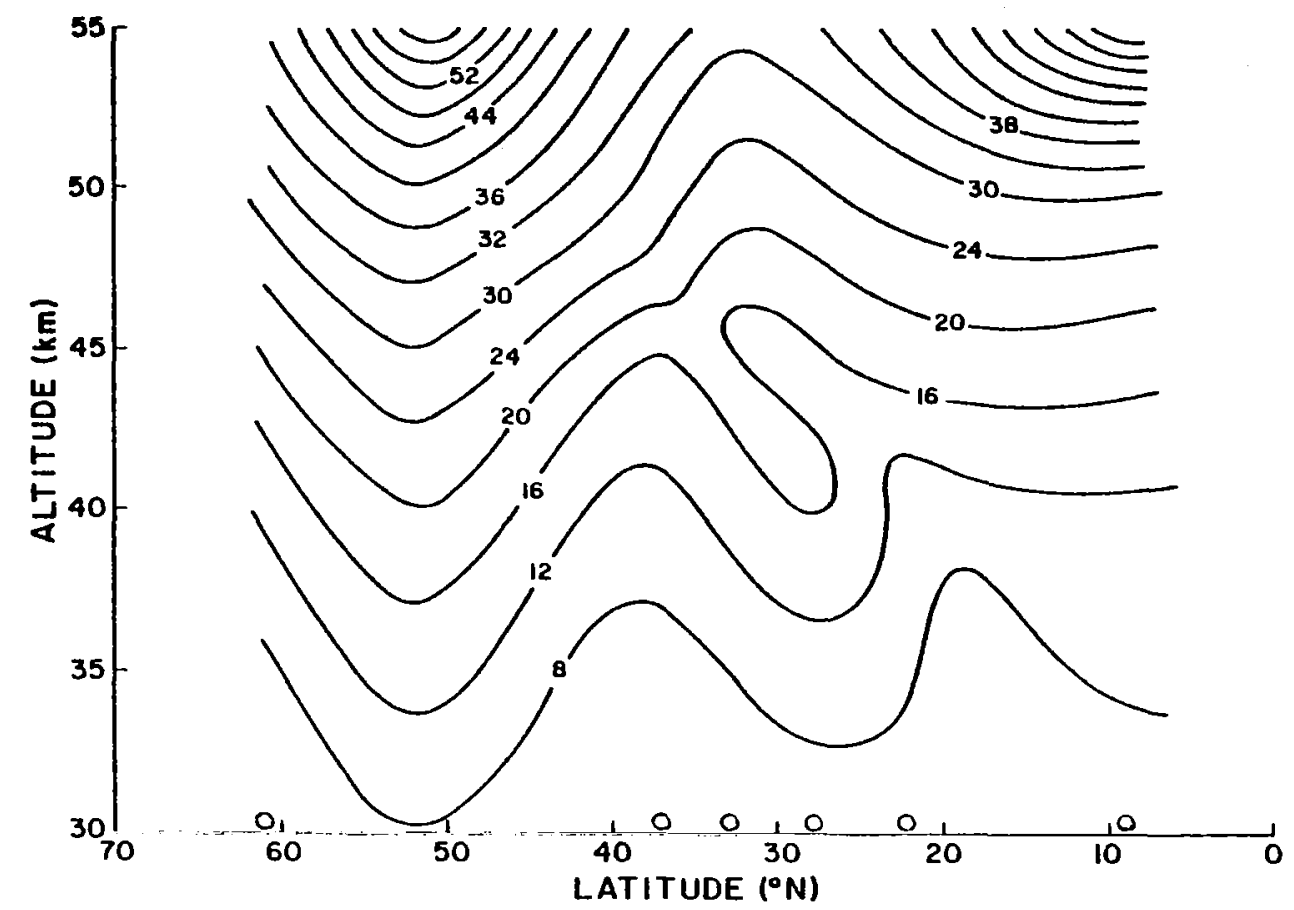

Fig. 14. Latitude-height section of the variance of the meridional wind $\left(\mathrm{m}^{2} \mathrm{sec}^{-2}\right)$, Spring 1969-1974. 


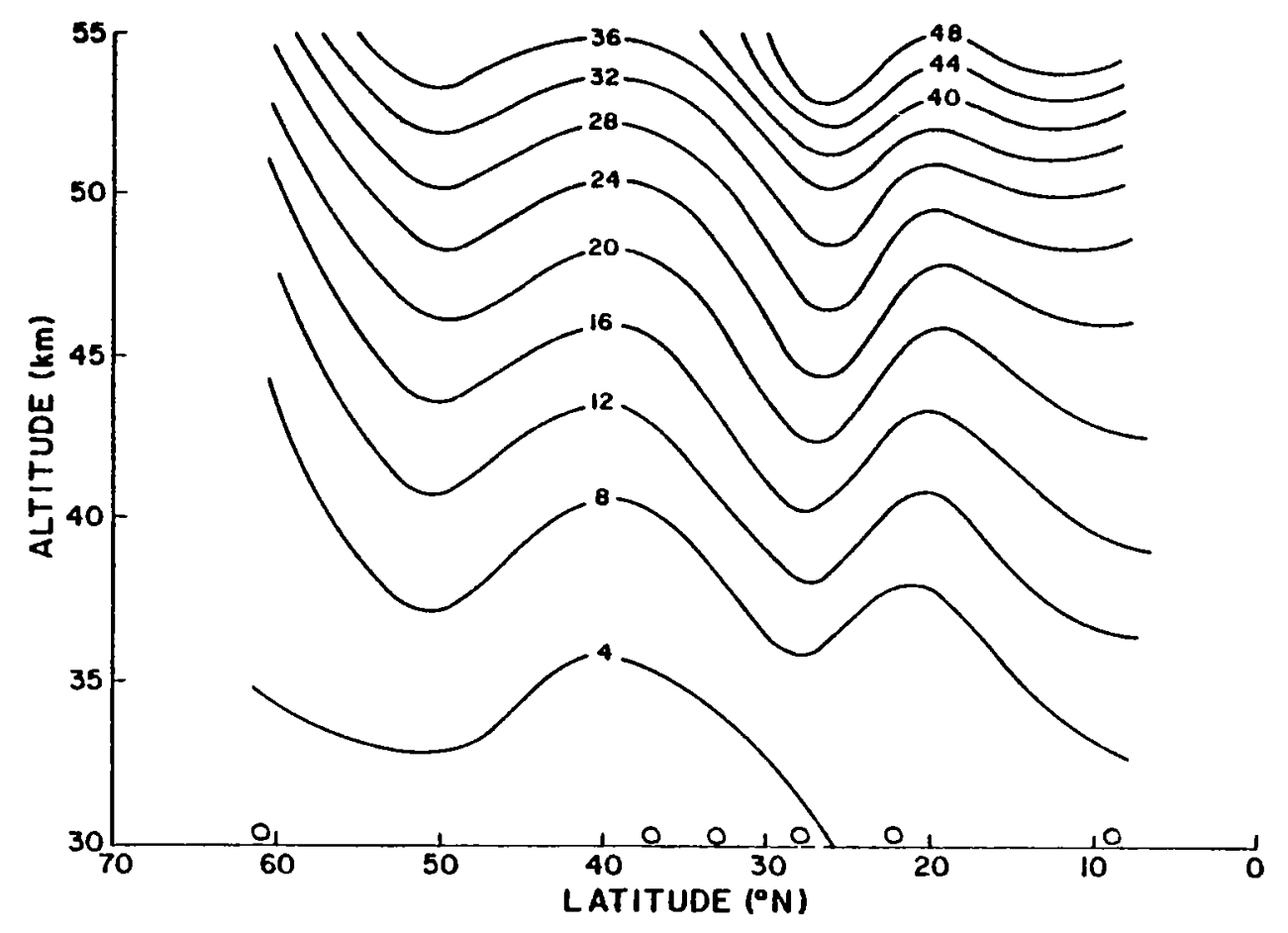

Fig. 15. Latitude-height section of the variance of the meridional wind $\left(\mathrm{m}^{2} \mathrm{sec}^{-2}\right)$, Summer 1969-1974. 


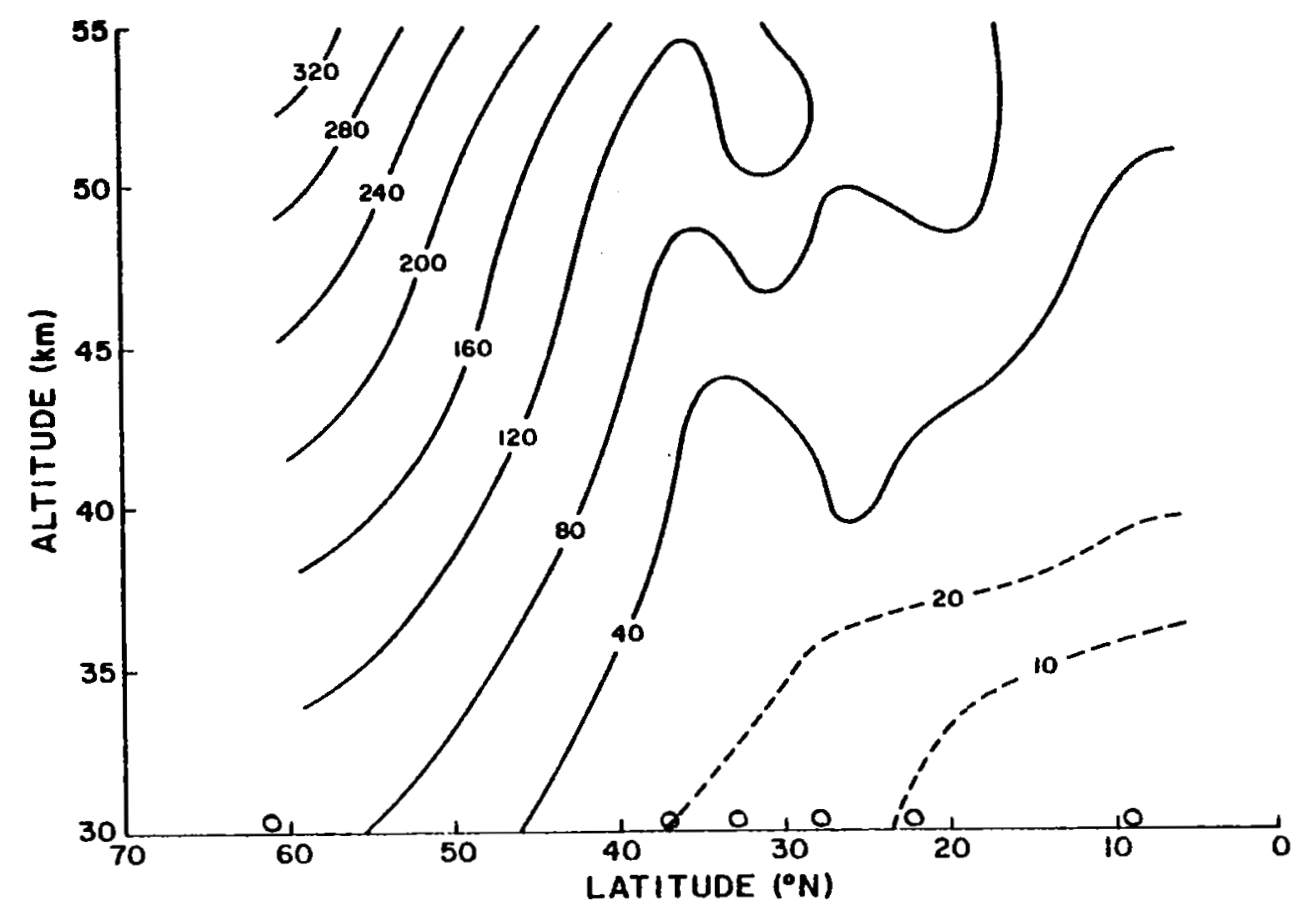

Fig. 16. Latitude-height section of the variance of the meridional wind $\left(\mathrm{m}^{2} \mathrm{sec}^{-2}\right)$, Fall 1969-1974. 


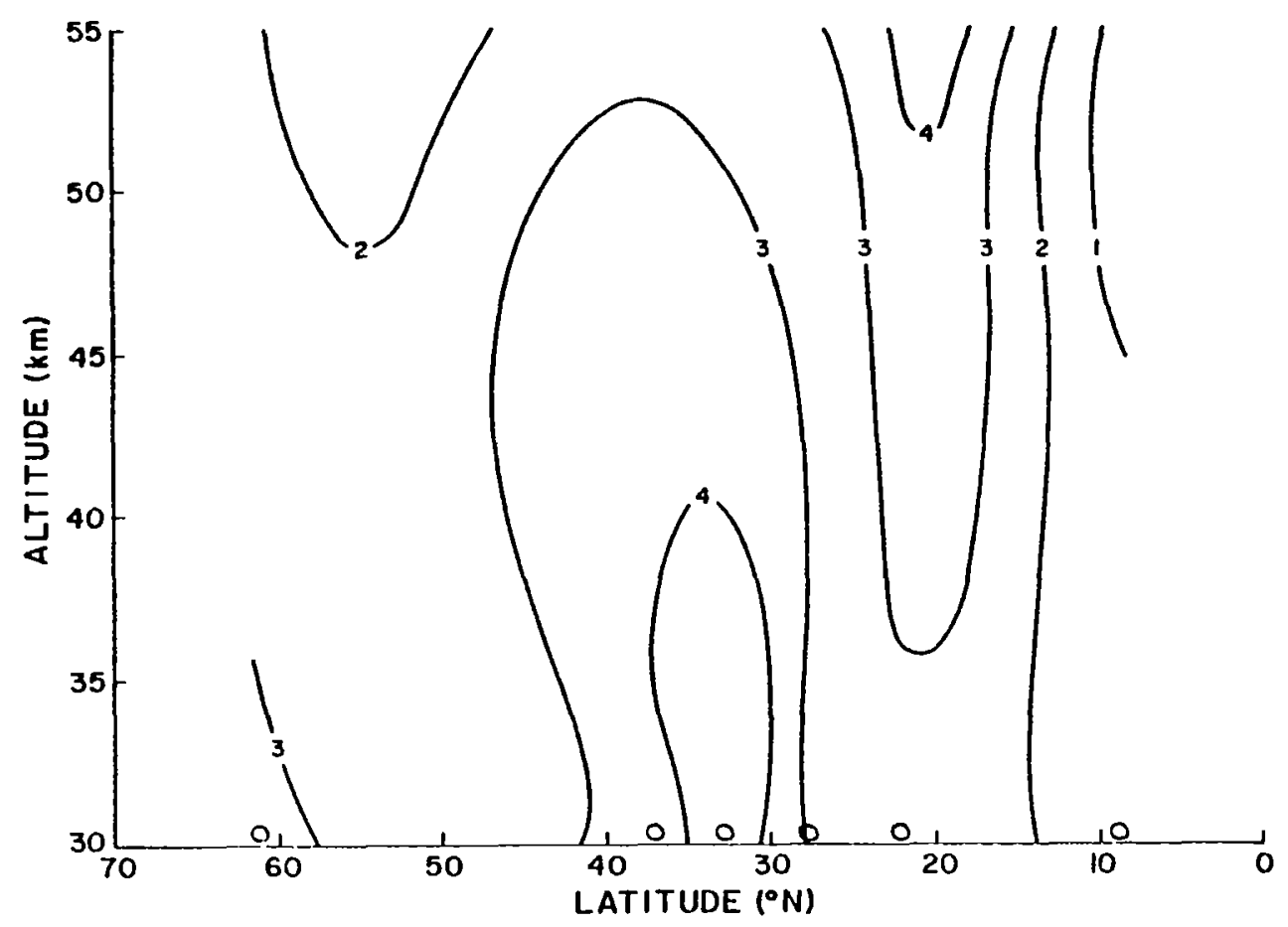

Fig. 17. Latitude-height section of the Eulerian integral time scale of the zonal component of turbulent velocity (day). Winter 19691974. 


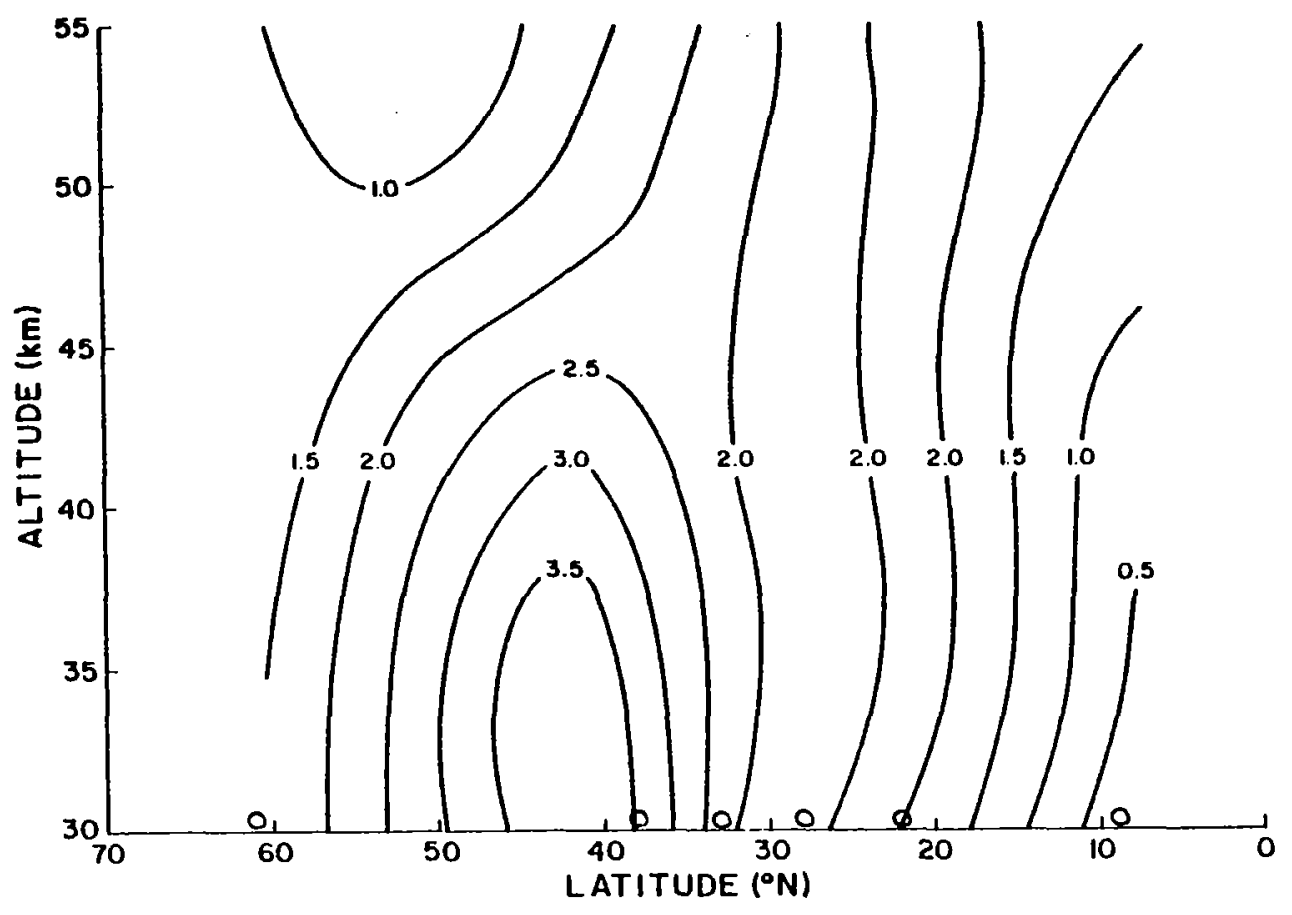

Fig. 18. Latitude-height section of the Eulerian integral time scale of the zonal component of turbulent velocity (day), Spring 19691974. 


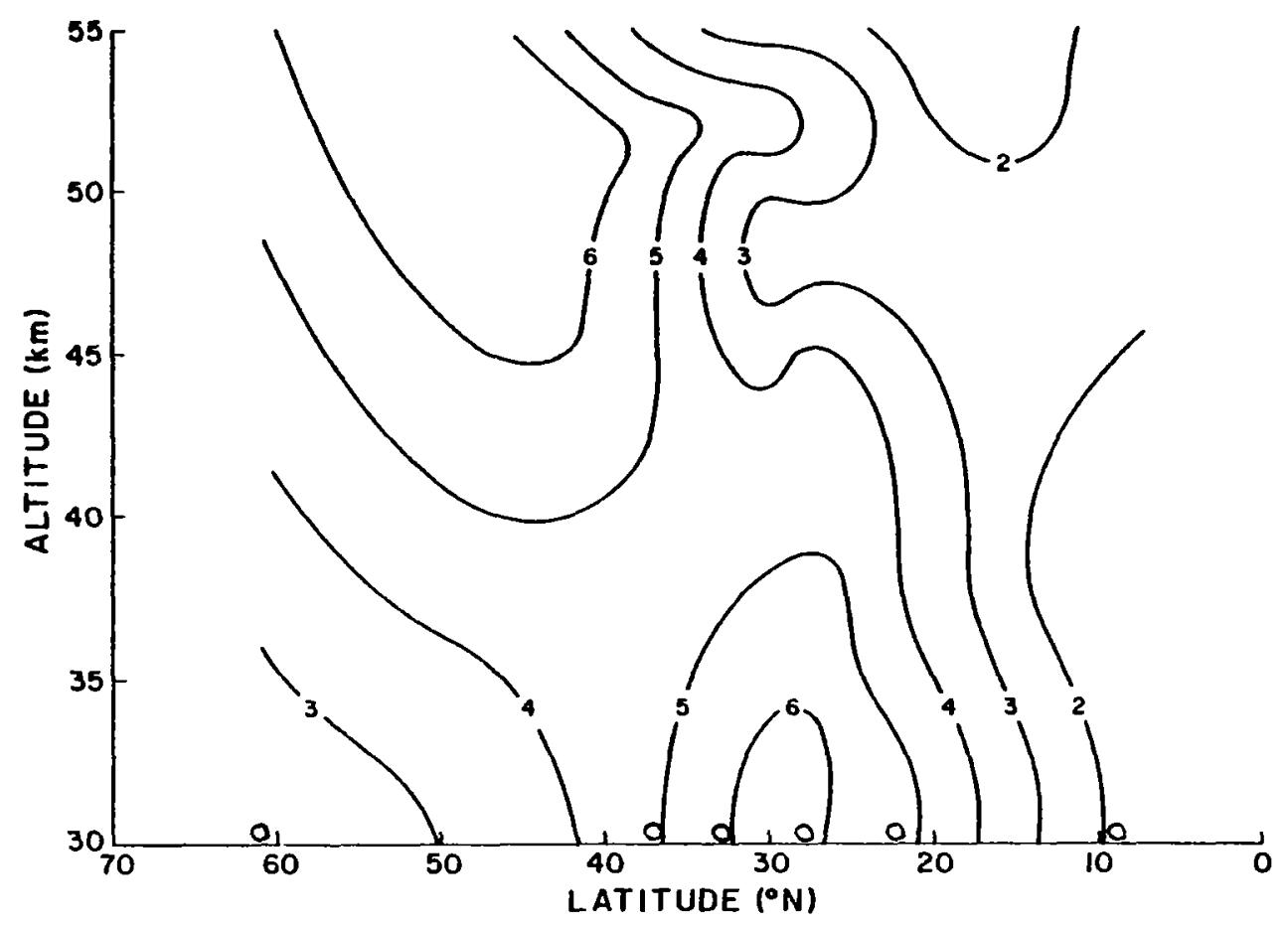

Fig. 19. Latitude-height section of the Eulerian integral time scale of the zonal component of turbulent velocity (day), Sumer 19691974. 


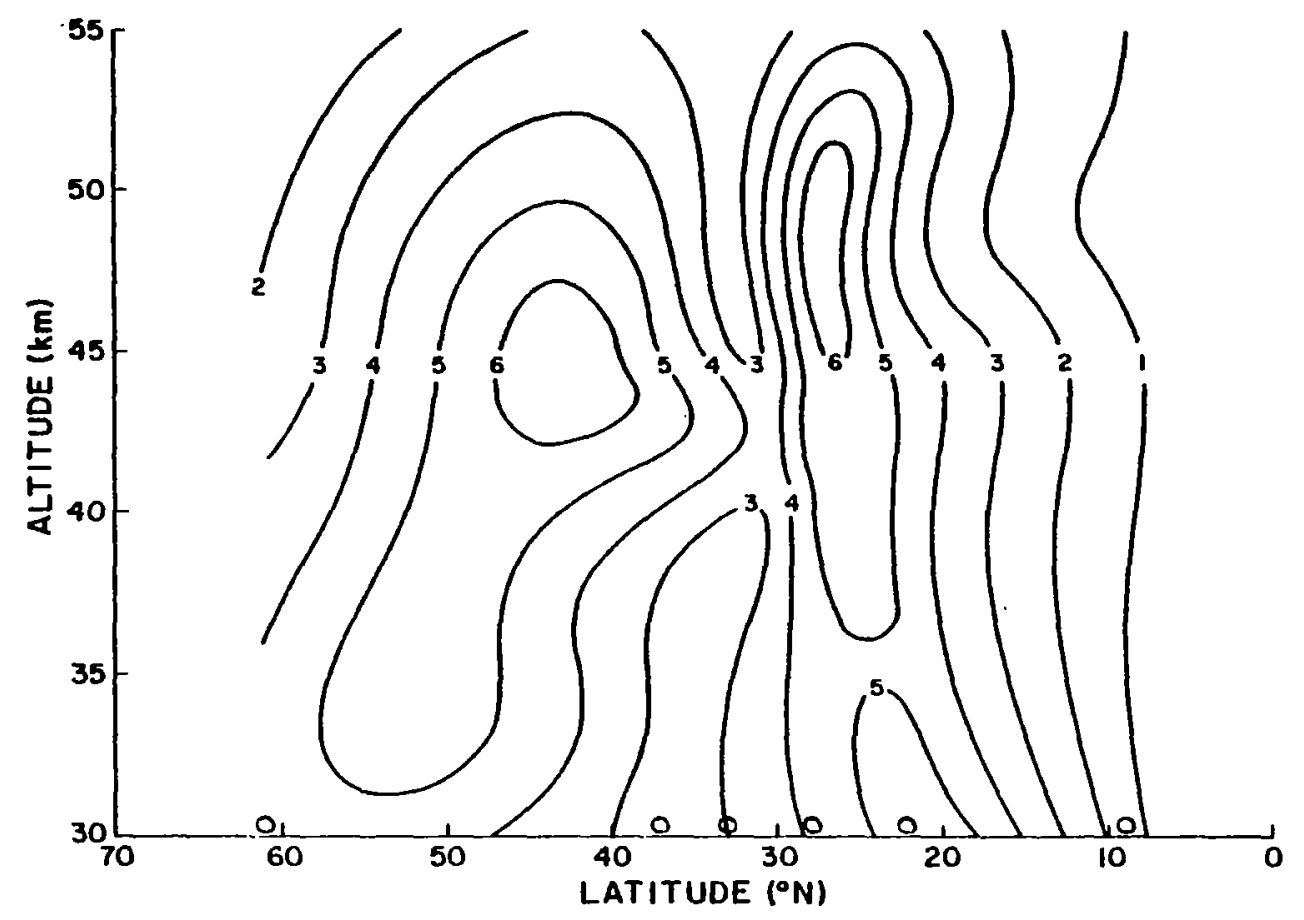

Fig. 20. Latitude-height section of the Eulerian integral time scale of the zonal component of turbulent velocity (day), Fall 19691974. 


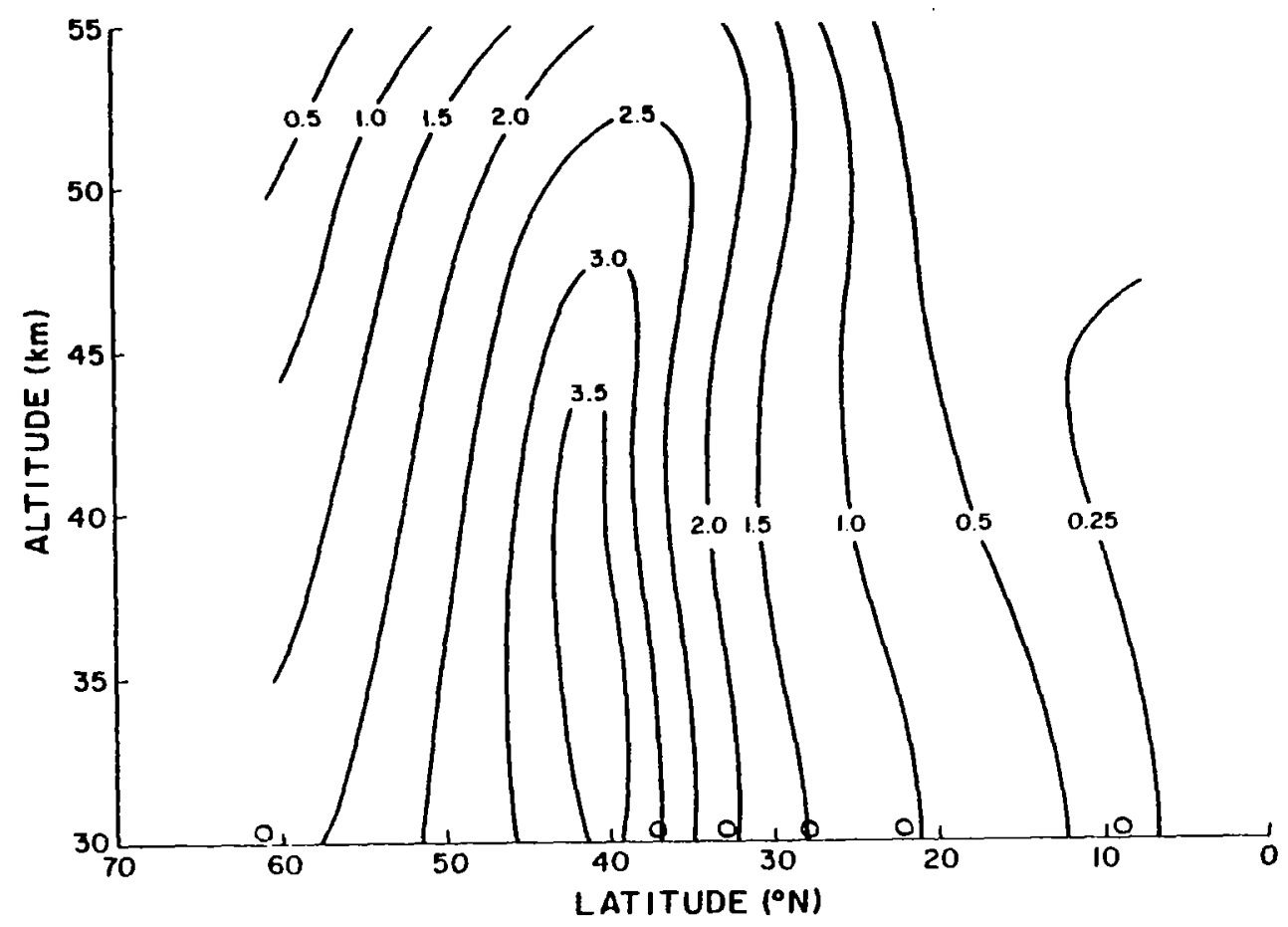

Fig. 21. Latitude-height section of the Eulerian integral time scale of the meridional component of turbulent velocity (day), Winter 1969-1974. 


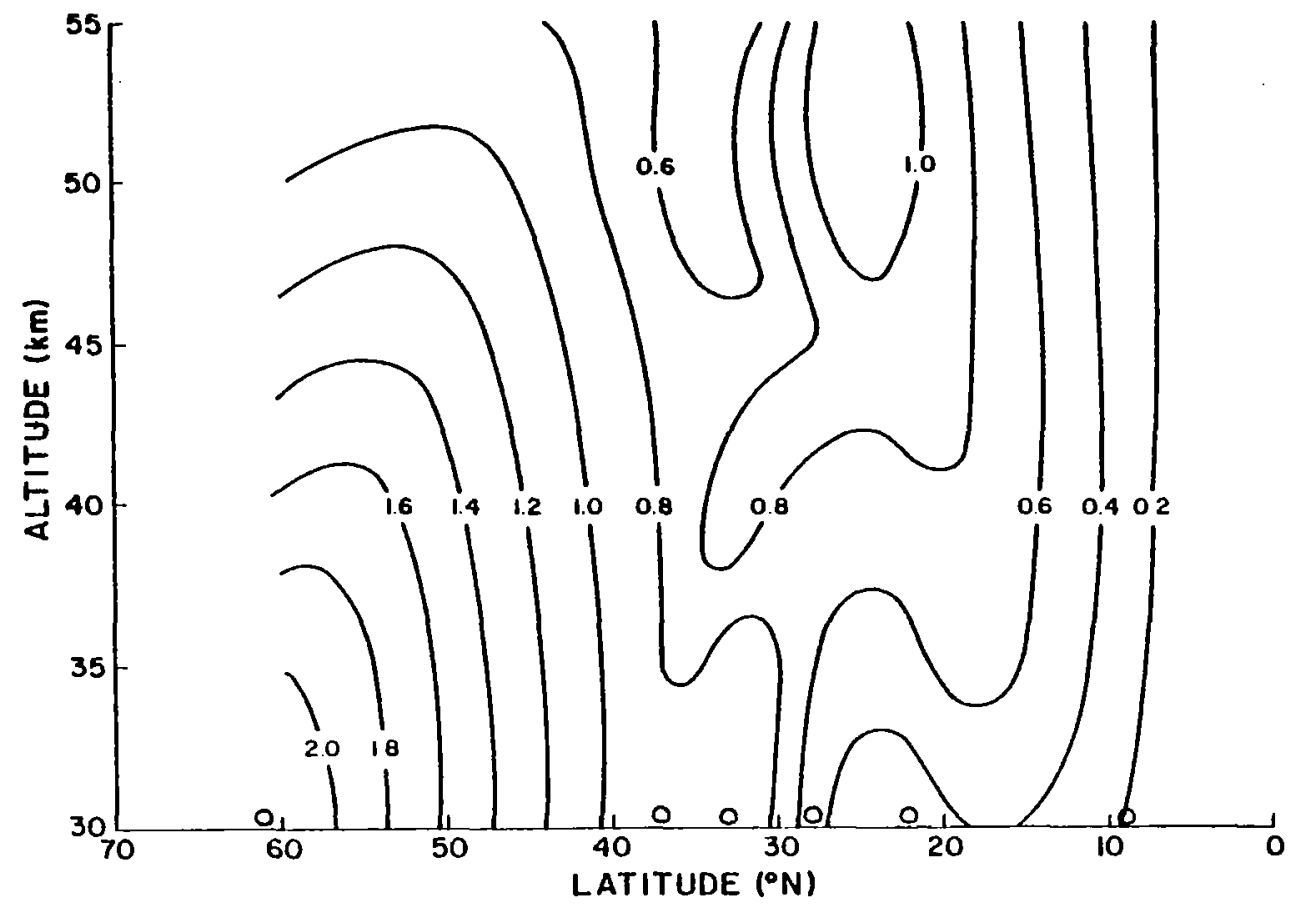

Fig. 22. Latitude-height section of the Eulerian integral time scale of the meridional component of turbulent velocity (day), Spring 1969-1974. 


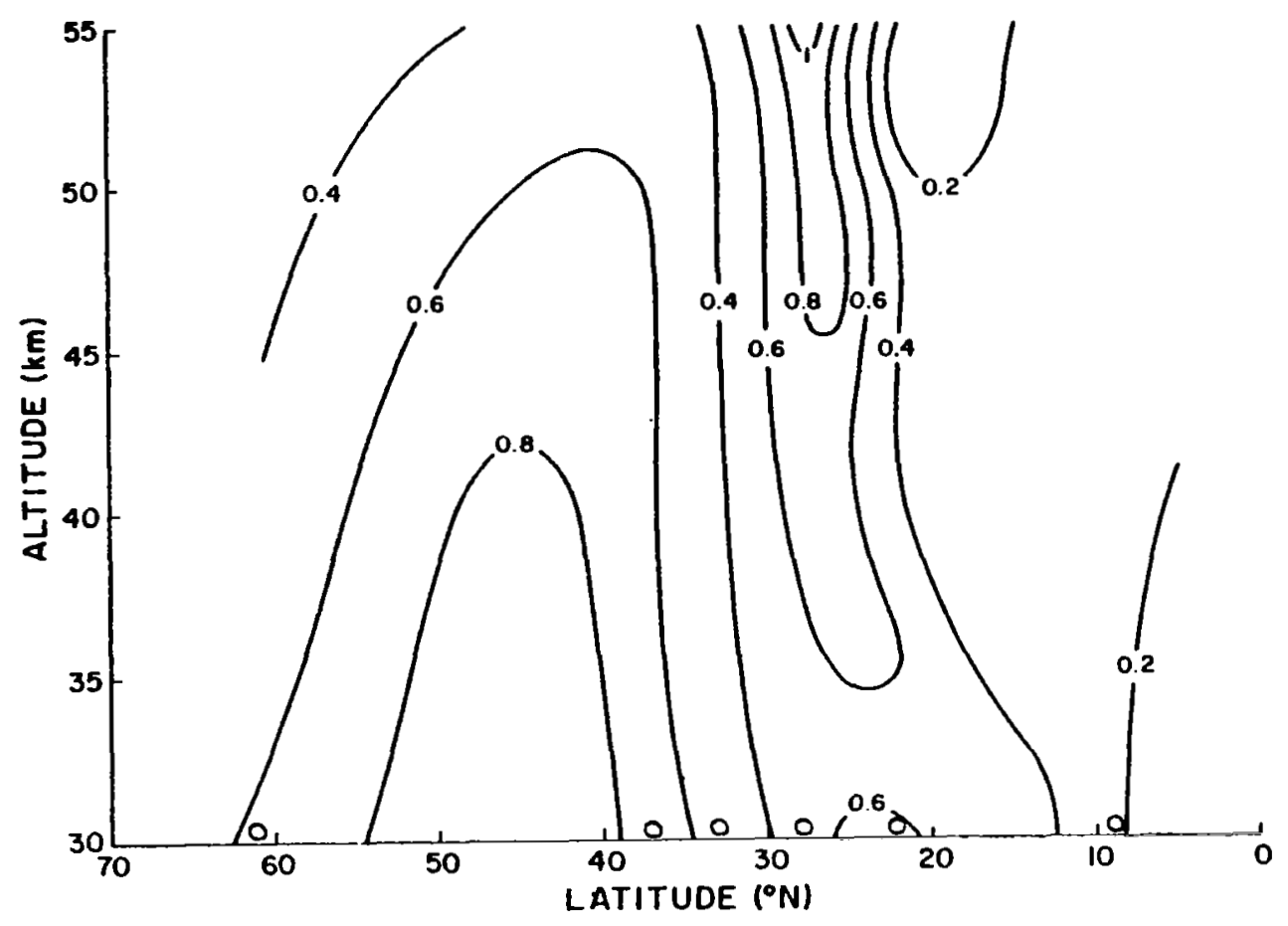

Fig. 23. Latitude-height section of the Eulerian integral time scale of the meridional component of turbulent velocity (day), Summer 1969-1974. 


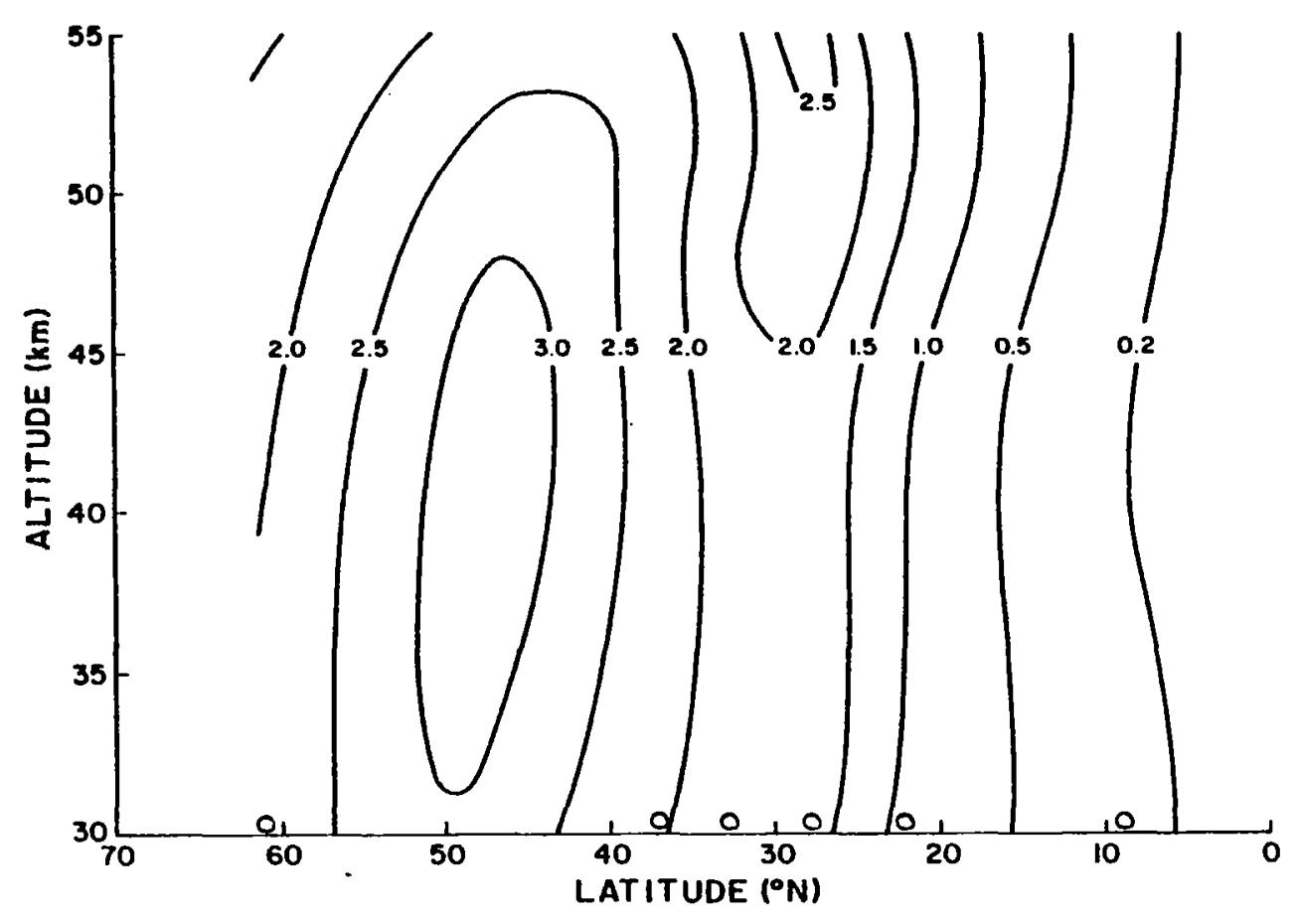

Fig. 24. Latitude-height section of the Eulerian integral time scale of the meridional component of turbulent velocity (day), Fall 1969-1974. 


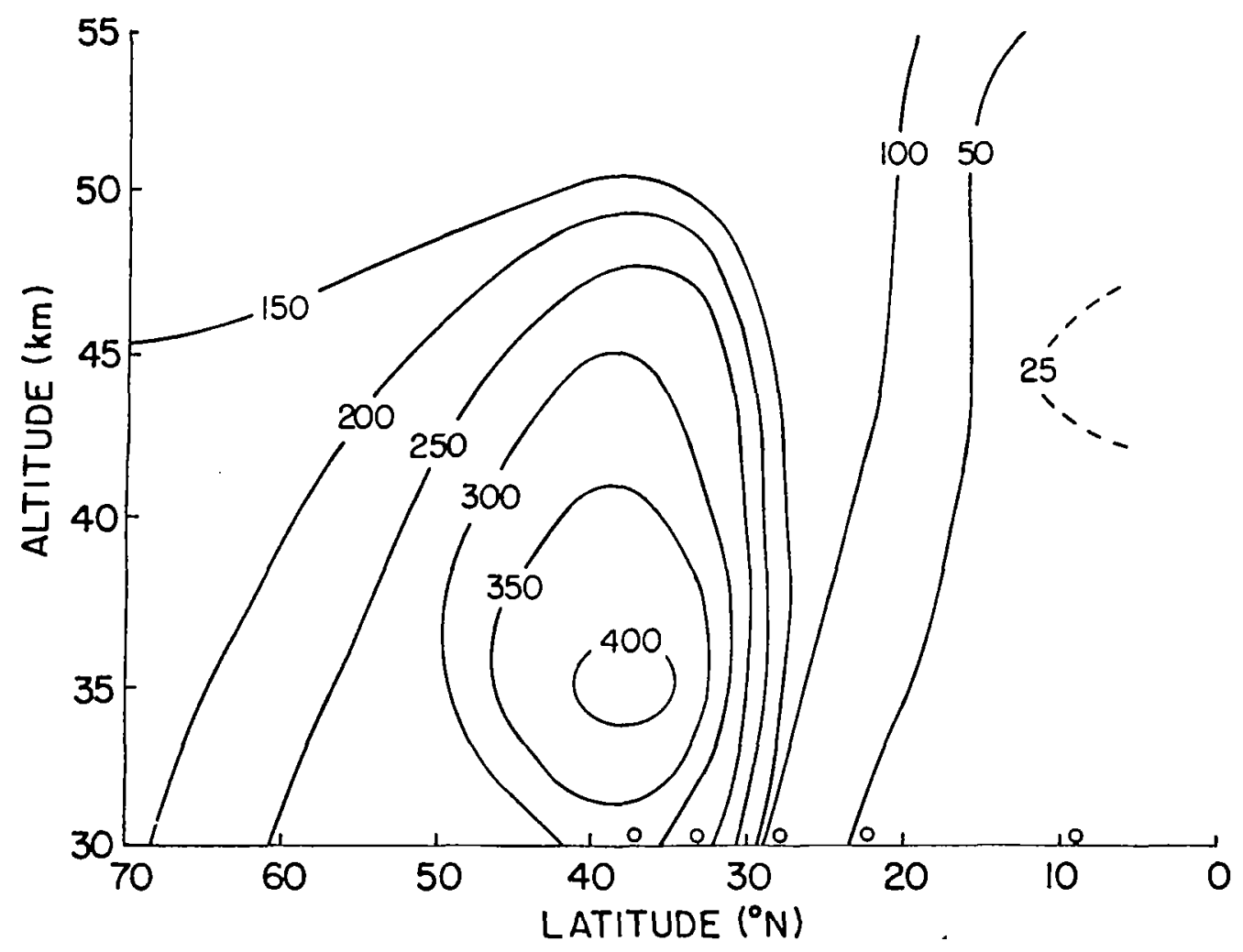

Fig. 25. Latitude-height section of the zonal component of eddy diffusivity $\left(10^{9} \mathrm{~cm}^{2} \mathrm{sec}^{-1}\right)$, Winter 1969-1974. 


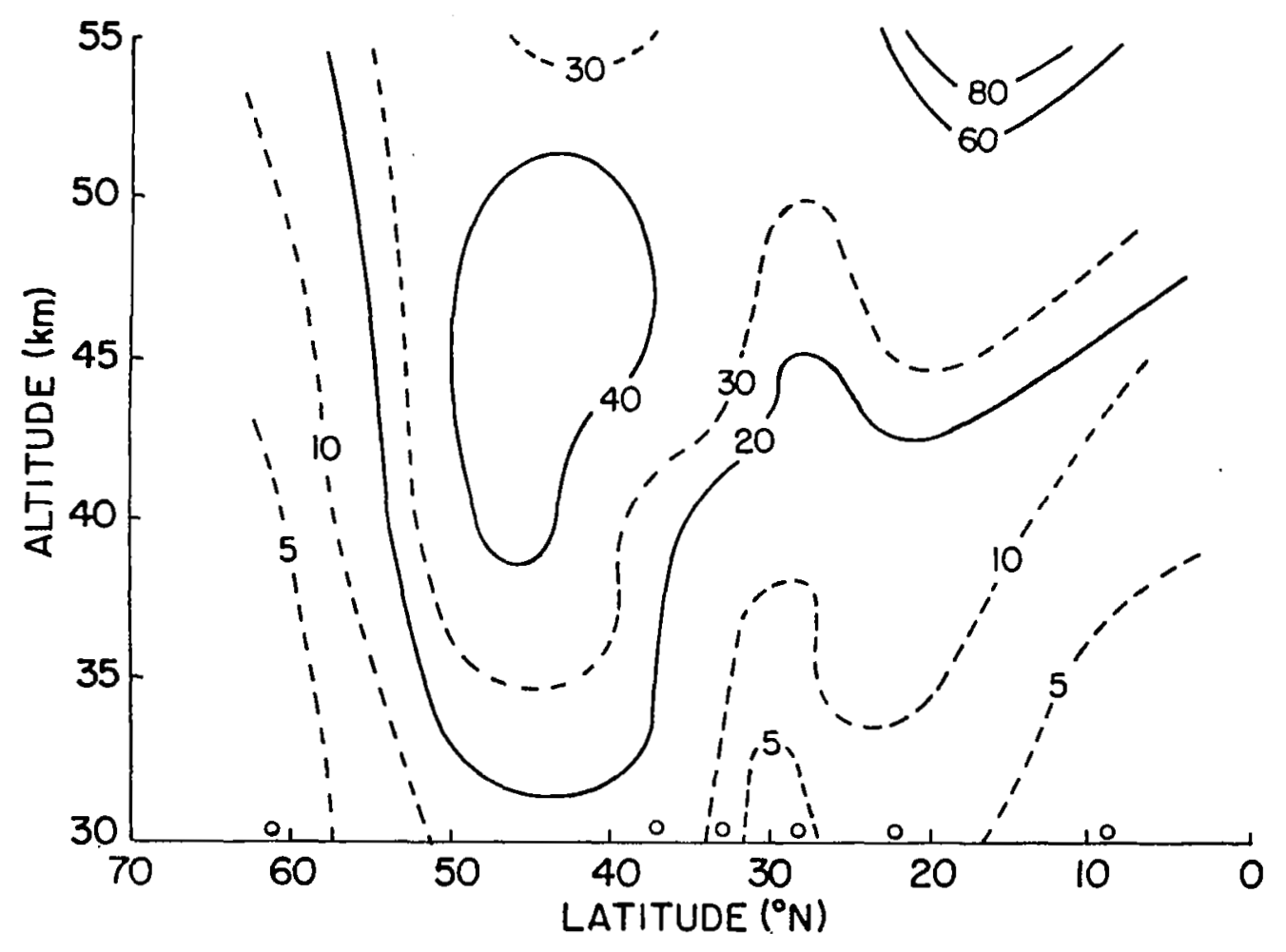

Fig. 26. Latitude-height section of the zonal component of eddy diffusivity $\left(10^{9} \mathrm{~cm}^{2} \mathrm{sec}^{-1}\right)$, Spring 1969-1974. 


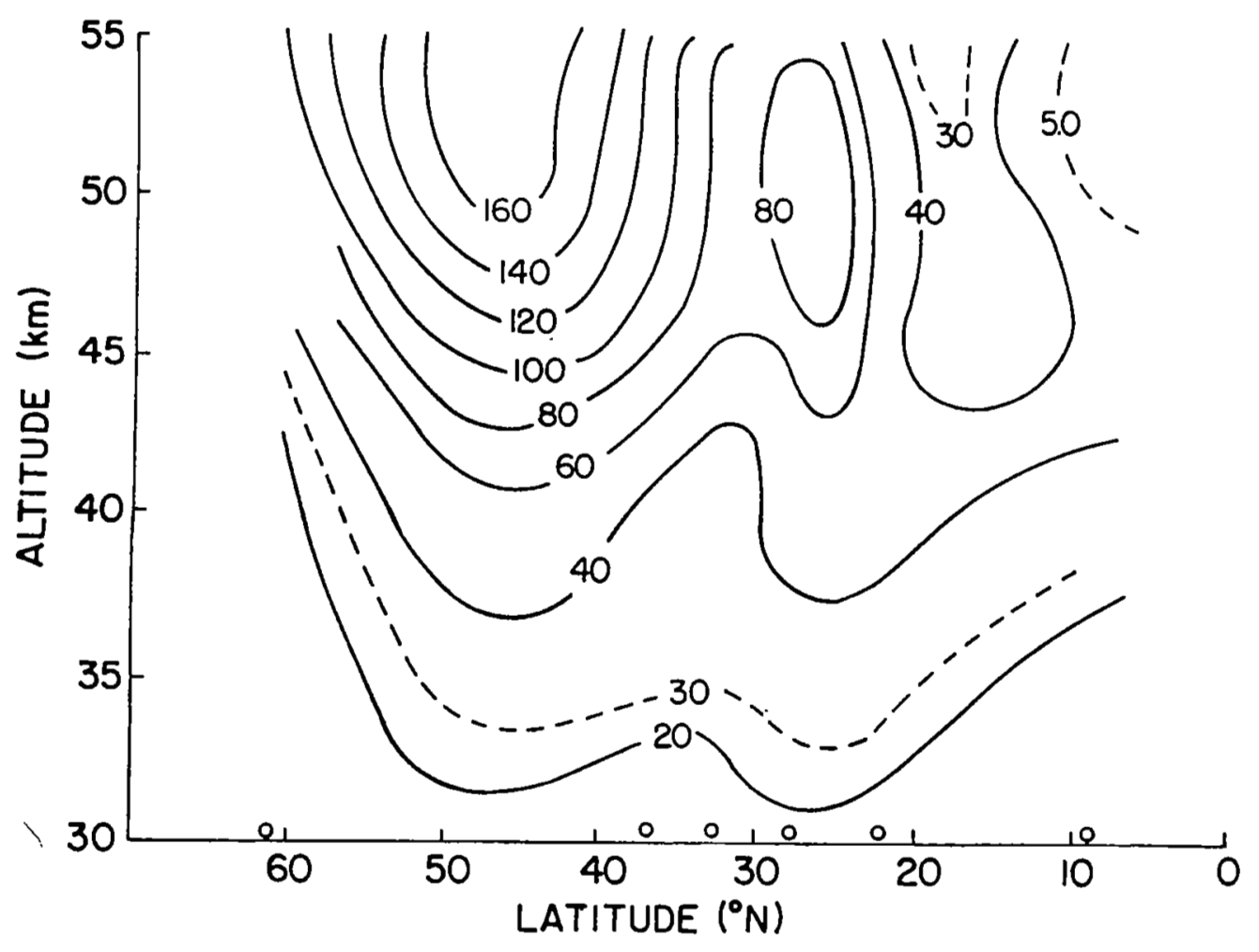

Fig. 27. Latitude-height section of the zonal component of eddy diffusivity $\left(10^{9} \mathrm{~cm}^{2} \mathrm{sec}^{-1}\right)$, Summer 1969-1974. 


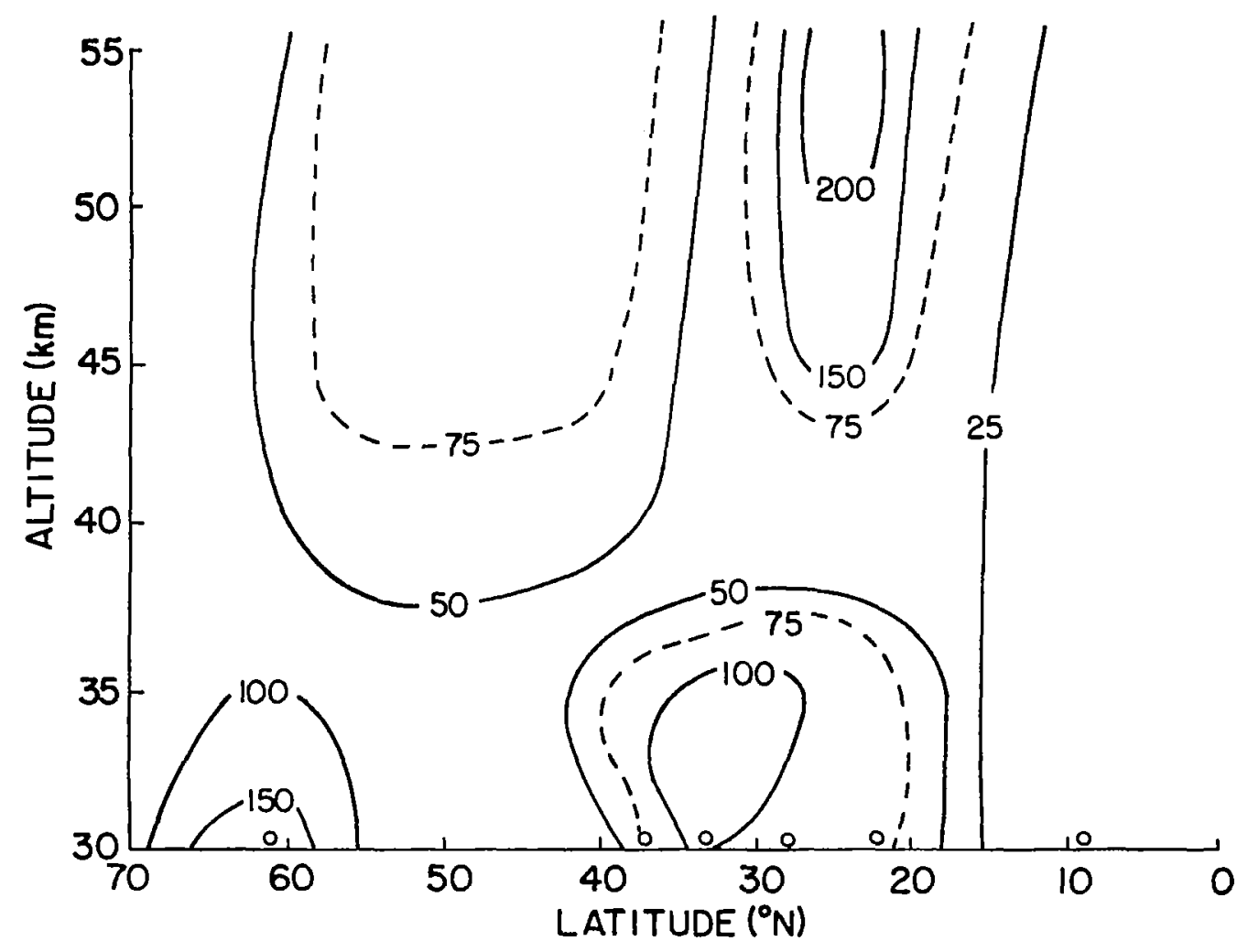

Fig. 28. Latitude-height section of the zonal component of eddy diffusivity $\left(10^{9} \mathrm{~cm}^{2} \mathrm{sec}^{-1}\right)$, Fall 1969-1974. 


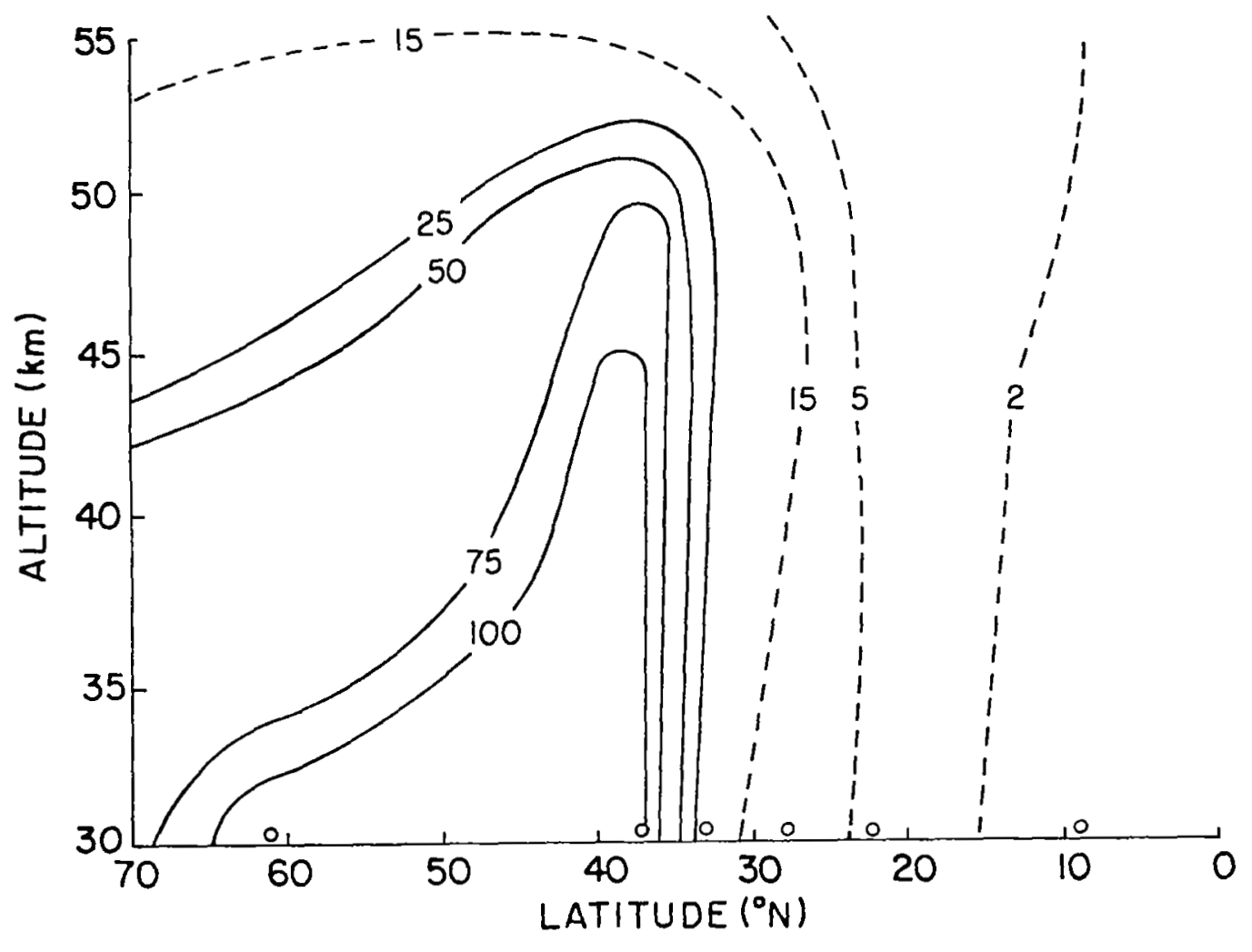

Fig. 29. Latitude-height section of the meridional component of eddy diffusivity $\left(10^{9} \mathrm{~cm}^{2} \mathrm{sec}^{-1}\right)$, Winter 1969-1974. 


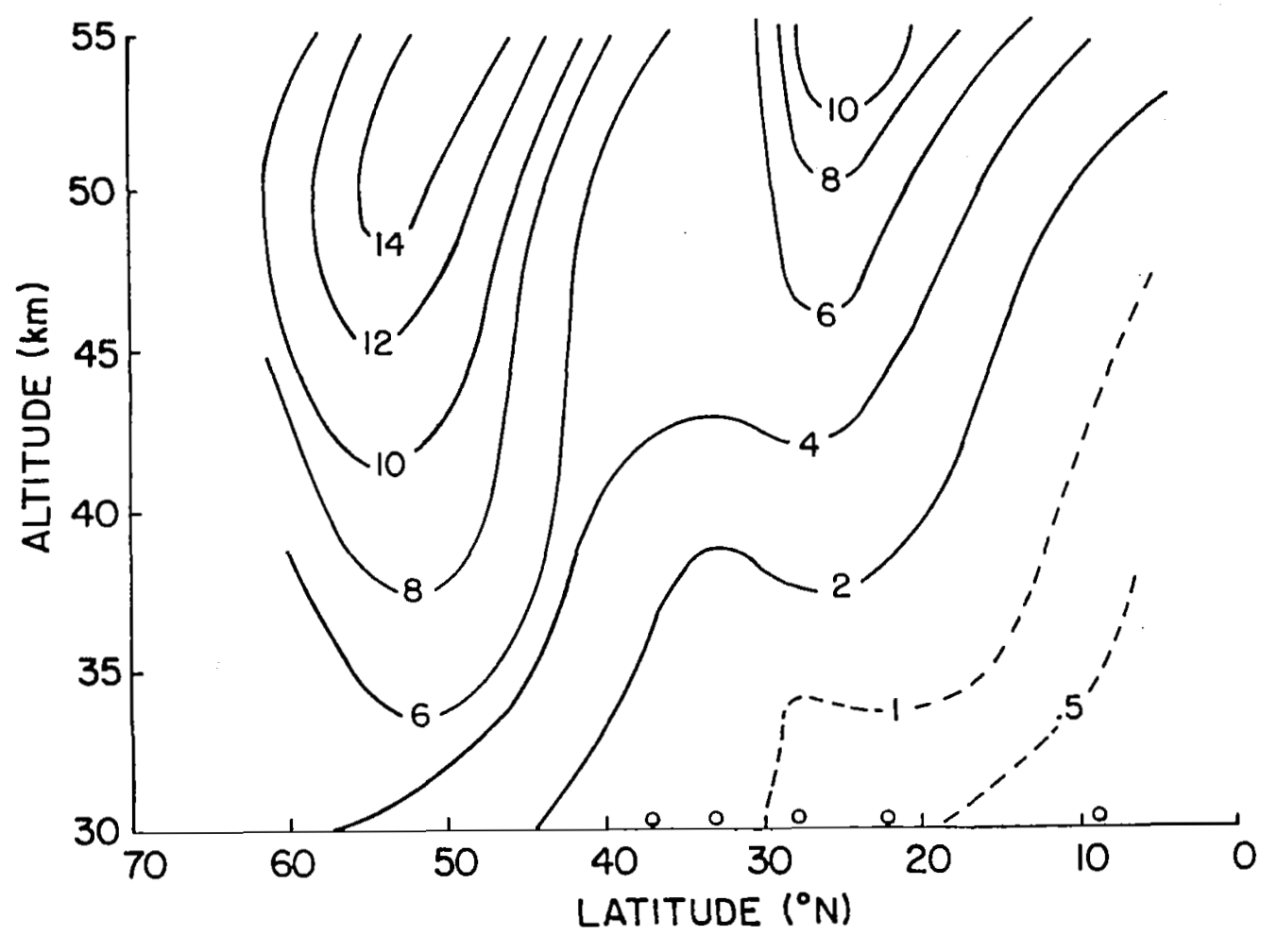

Fig. 30. Latitude-height section of the meridional component of eddy diffusivity $\left(10^{9} \mathrm{~cm}^{2} \mathrm{sec}^{-1}\right)$, Spring 1969-1974. 


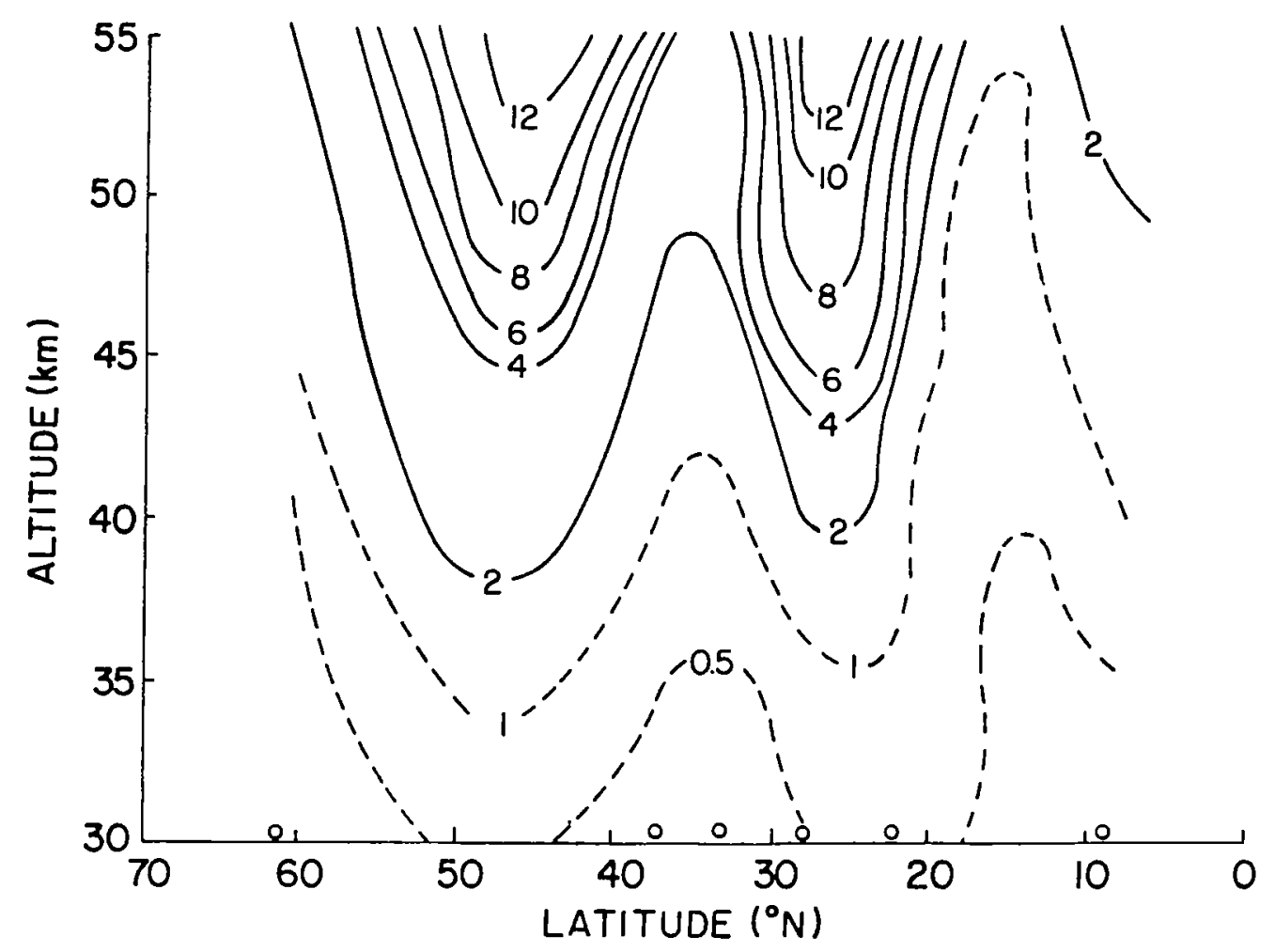

Fig. 31. Latitude-height section of the meridional component of eddy
diffusivity $\left(10^{9} \mathrm{~cm}^{2} \mathrm{sec}^{-1}\right)$, Suminer 1969-1974. 


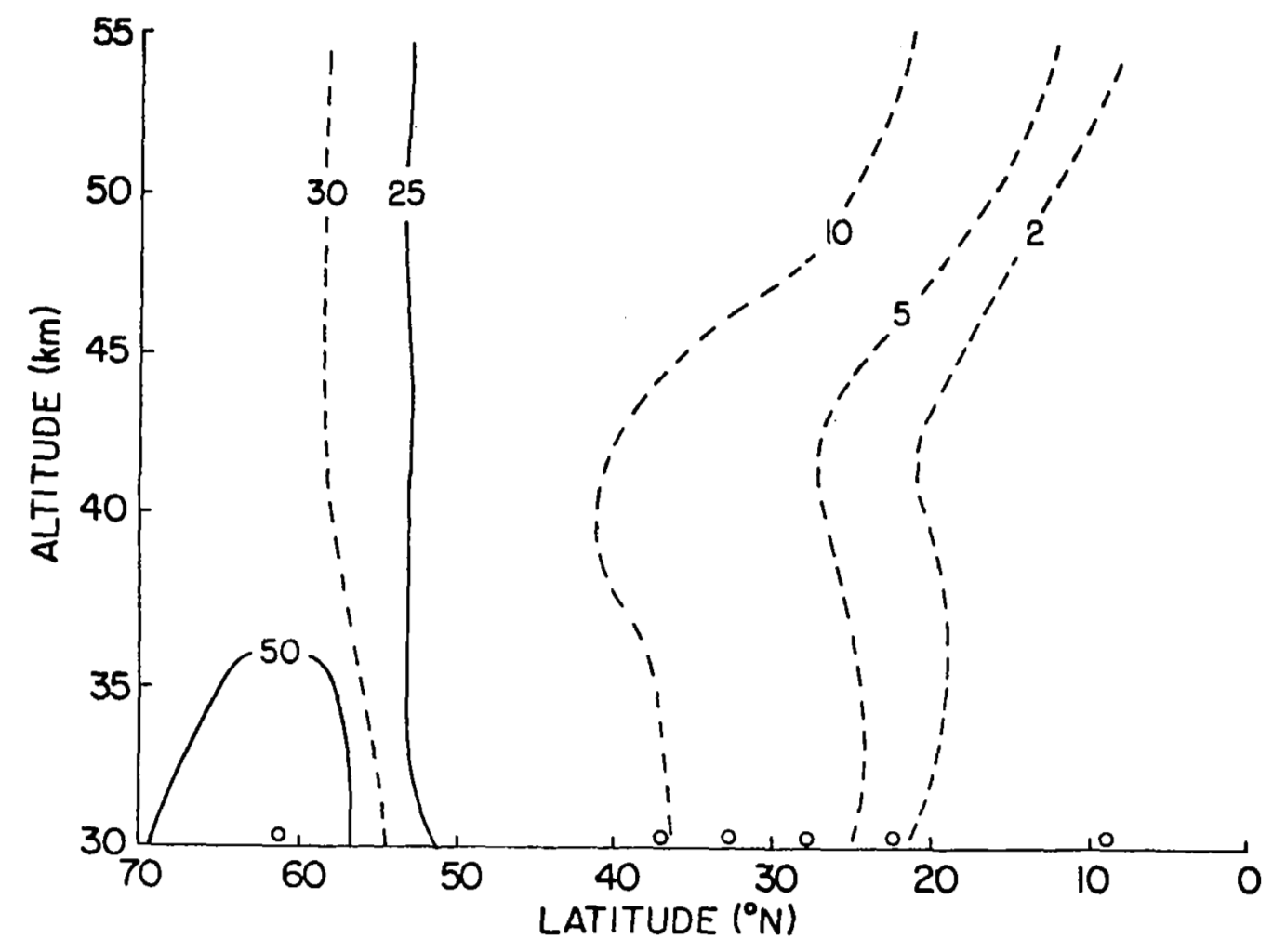

Fig. 32. Latitude-height section of the meridional component of eddy diffusivity $\left(10^{9} \mathrm{~cm}^{2} \mathrm{sec}^{-1}\right)$, Fall 1969-1974. 


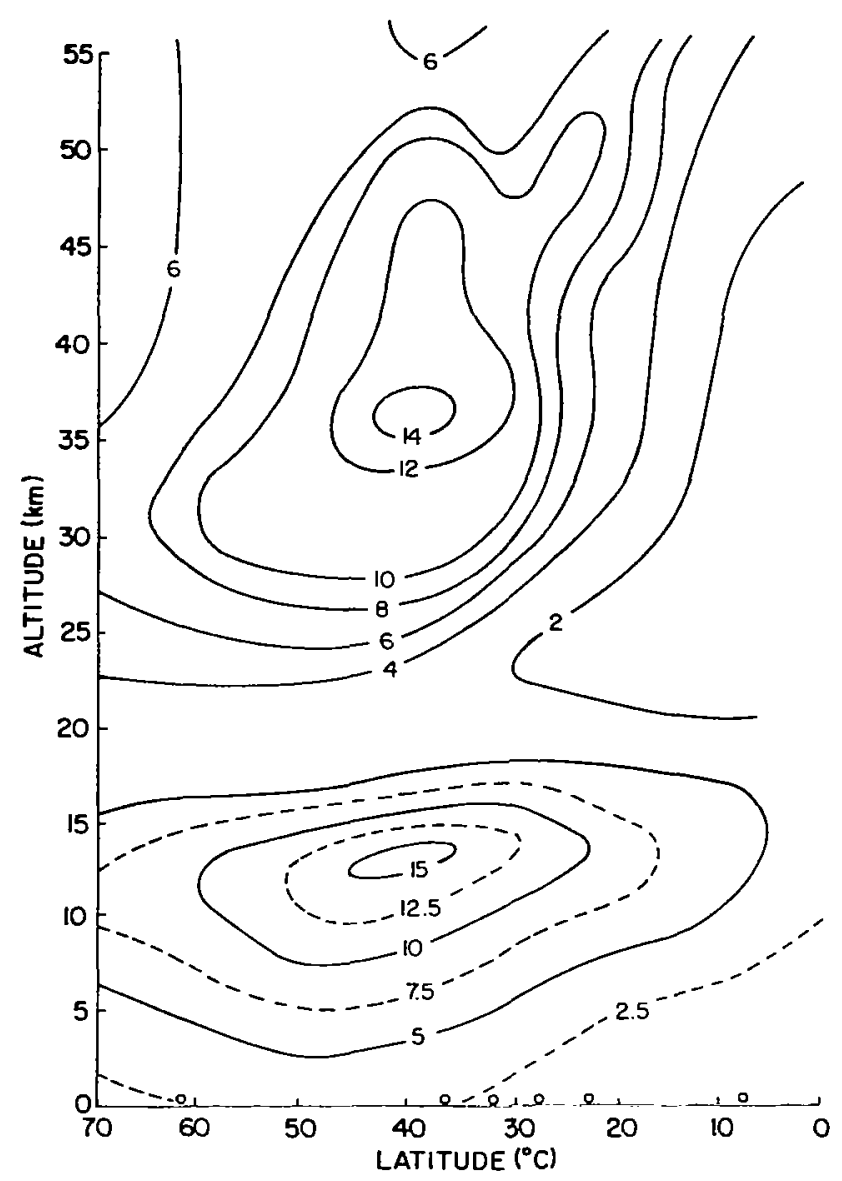

Fig. 33. Latitude-height section of the zonal component of eddy diffusivity $\left(10^{10} \mathrm{~cm}^{2} \sec ^{-1}\right)$, annual mean. 


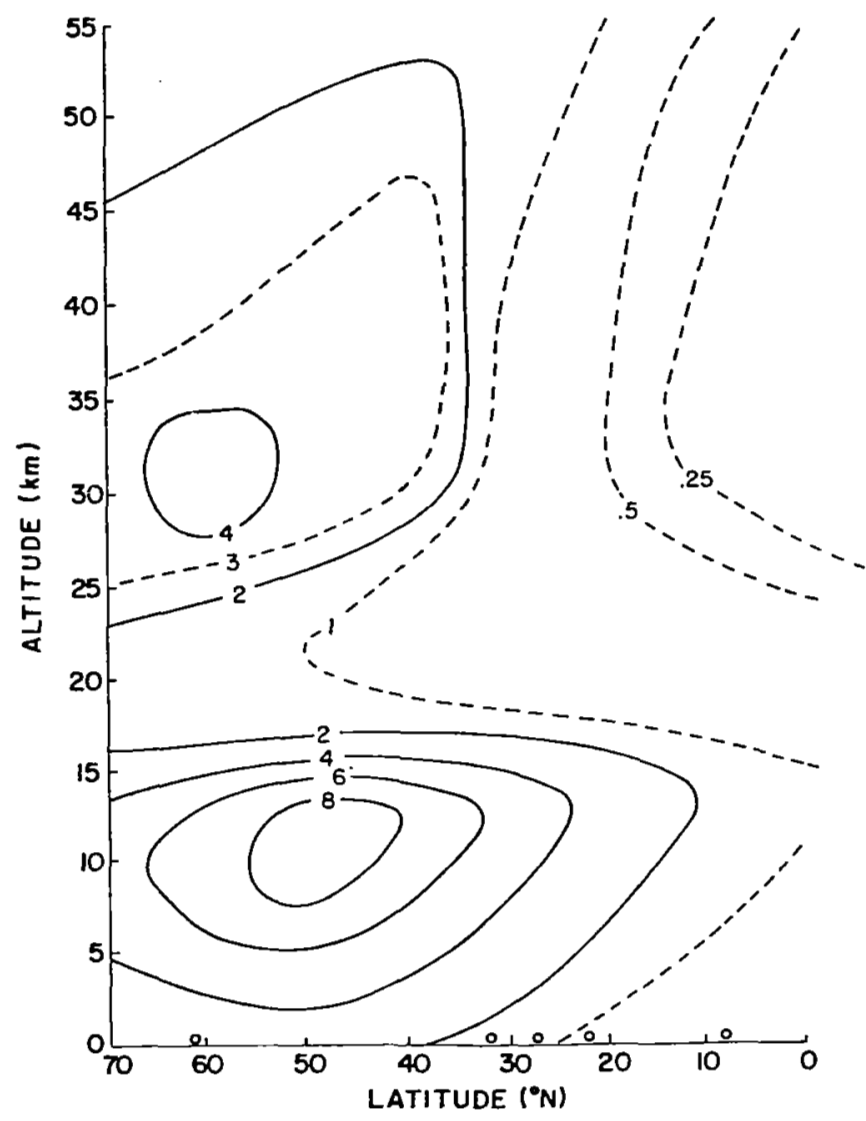

Fig. 34. Latitude-height section of the meridional component of eddy diffusivity $\left(10^{10} \mathrm{~cm}^{2} \mathrm{sec}^{-1}\right)$, annual mean 
APPENDIX

TABLES OF THE RESULTS

Rocketsonde locations are identified by the following number:

$1=$ Ft. Churchill, Ft. Greely, Poker Flats

$2=$ Wallops Is land

3 = Pt. Mugu, White Sands

4 = Cape Kennedy

5 = Barking Sands

$6=$ Ft. Sherman, Kwajalein 
Table 1. Mean zonal wind $\left(\mathrm{m} \mathrm{sec}^{-1}\right)$, Winter 1969-1974.

\begin{tabular}{|c|c|c|c|c|c|c|}
\hline Alt & 1 & 2 & $\begin{array}{l}\text { Station } \\
3\end{array}$ & 4 & 5 & 6 \\
\hline 55 & 27.3 & 57.0 & 44.6 & 30.2 & 35.7 & 18.7 \\
\hline 50 & 27.3 & 53.5 & 39.7 & 20.3 & 18.9 & -1.1 \\
\hline 45 & 25.4 & 47.4 & 33.5 & 14.5 & 8.8 & -11.1 \\
\hline 40 & 20.0 & 37.4 & 26.2 & 13.4 & 1.5 & -12.5 \\
\hline 35 & 15.6 & 28.6 & 18.4 & 17.2 & 6.3 & -12.8 \\
\hline 30 & 13.1 & 16.4 & 7.6 & 11.6 & 7.8 & -5.1 \\
\hline
\end{tabular}

Table 2. Mean zonal wind $\left(\mathrm{m} \mathrm{sec}^{-1}\right)$, Spring 1969-1974.

\begin{tabular}{lrrrrrr} 
A7t & 1 & 2 & $3^{\text {Station }}$ & 4 & 5 & 6 \\
\hline 55 & -15.5 & -20.4 & -24.2 & -24.3 & -20.2 & -2.5 \\
50 & -9.8 & -15.1 & -20.0 & -20.4 & -20.0 & -10.2 \\
45 & -7.6 & -11.4 & -15.2 & -18.6 & -22.4 & -3.3 \\
40 & -7.7 & -6.1 & -7.9 & -10.6 & -17.3 & -11.5 \\
35 & -7.0 & -1.2 & -2.2 & -4.6 & -14.0 & -20.2 \\
30 & -6.6 & -.8 & -3.0 & -5.5 & -12.0 & -17.3 \\
\hline
\end{tabular}


Table 3. Mean zonal wind $\left(m \mathrm{sec}^{-1}\right)$, Sumer 1969-1974.

\begin{tabular}{lcccccr}
\hline A1t & 1 & 2 & $3^{\text {Station }}$ & 4 & 5 & 6 \\
\hline 55 & -12.9 & -34.1 & -29.8 & -26.0 & -14.4 & -.7 \\
50 & -7.9 & -28.6 & -31.6 & -32.8 & -27.0 & -10.6 \\
45 & -5.0 & -26.9 & -30.0 & -33.8 & -32.8 & -21.3 \\
40 & -3.0 & -21.5 & -22.8 & -26.1 & -30.3 & -27.8 \\
35 & -3.5 & -15.5 & -17.9 & -22.4 & -28.0 & -26.7 \\
30 & -3.0 & -13.2 & -17.7 & -22.8 & -26.5 & -22.5 \\
\hline
\end{tabular}

Table 4. Mean zonal wind (m $\mathrm{sec}^{-1}$ ), Fall 1969-1974.

\begin{tabular}{lllllll}
\hline A1t & 1 & 2 & $3^{\text {Station }}$ & 4 & 5 & 6 \\
\hline 55 & 41.9 & 83.7 & 68.4 & 47.3 & 45.0 & 16.7 \\
50 & 44.6 & 75.9 & 63.6 & 43.8 & 42.0 & 10.0 \\
45 & 42.8 & 64.0 & 50.6 & 37.7 & 33.7 & 8.9 \\
40 & 32.4 & 48.8 & 40.0 & 31.5 & 21.5 & 7.0 \\
35 & 26.4 & 37.5 & 25.7 & 24.2 & 11.1 & -2.3 \\
30 & 20.4 & 21.4 & 11.3 & 10.4 & .8 & -4.0 \\
\hline
\end{tabular}


Table 5. Mean meridonal wind $\left(\mathrm{m} \mathrm{sec}^{-1}\right)$, Winter 1969-1974.

\begin{tabular}{lrrrrrr}
\hline A1t & 1 & 2 & $3^{\text {Station }}$ & \multicolumn{1}{c}{4} & 5 & 6 \\
\hline 55 & -5.9 & 16.6 & 10.3 & 9.0 & 7.3 & 2.4 \\
50 & -9.2 & 15.7 & 9.8 & 7.4 & 6.4 & 5.3 \\
45 & -11.7 & 13.3 & 5.5 & 5.7 & 5.1 & 2.2 \\
40 & -15.0 & 6.2 & .2 & 1.0 & 1.5 & 1.9 \\
35 & -14.3 & 1.7 & 1.4 & .5 & .5 & .3 \\
30 & -12.5 & 2.5 & -.1 & 3.1 & 1.2 & .8 \\
\hline
\end{tabular}

Table 6. Mean meridional wind ( $\mathrm{m} \mathrm{sec}^{-1}$ ), Spring 1969-1974.

\begin{tabular}{lrrrrrr}
\hline A1t & 1 & 2 & $3^{\text {Station }}$ & 4 & 5 & 6 \\
\hline 55 & 5.7 & 6.5 & 5.3 & 4.7 & 7.4 & 4.8 \\
50 & 3.8 & 5.3 & 6.5 & 5.3 & 6.2 & 5.2 \\
45 & 1.8 & 3.7 & 3.9 & 1.3 & 5.1 & 2.5 \\
40 & 1.9 & .8 & -.1 & -.8 & .3 & 1.9 \\
35 & 1.5 & .9 & 1.1 & -.2 & .6 & .4 \\
30 & .9 & 1.5 & 1.0 & 1.2 & 1.2 & 1.4 \\
\hline
\end{tabular}


Table 7. Mean meridional wind $\left(\mathrm{m} \mathrm{sec}^{-1}\right)$, Summer 1969-1974.

\begin{tabular}{|c|c|c|c|c|c|c|}
\hline \multirow[b]{2}{*}{ A1t } & \multirow[b]{2}{*}{1} & \multicolumn{4}{|c|}{ Station } & \multirow[b]{2}{*}{6} \\
\hline & & 2 & 3 & 4 & 5 & \\
\hline 55 & 4.8 & 4.6 & 5.7 & 6.3 & 6.6 & 5.4 \\
\hline 50 & 3.1 & 6.3 & 5.8 & 4.6 & 5.7 & 5.0 \\
\hline 45 & 2.0 & 4.7 & 2.7 & .4 & 3.8 & 2.9 \\
\hline 40 & 1.6 & 1.2 & .0 & -.6 & .3 & 1.0 \\
\hline 35 & 1.7 & .9 & 1.2 & .7 & 1.5 & .1 \\
\hline 30 & .8 & .9 & .6 & -.2 & .8 & 1.1 \\
\hline
\end{tabular}

Table 8. Mean meridional wind (m sec ${ }^{-1}$ ), Fall 1969-1974.

\begin{tabular}{|c|c|c|c|c|c|c|}
\hline Alt & 1 & 2 & Station & 4 & 5 & 6 \\
\hline 55 & -6.3 & 13.6 & 13.0 & 8.5 & 6.3 & 2.0 \\
\hline 50 & -8.7 & 14.9 & 12.9 & 10.0 & 7.5 & 2.7 \\
\hline 45 & -11.8 & 12.4 & 6.2 & 7.3 & 5.3 & 2.2 \\
\hline 40 & -14.3 & 5.4 & 1.4 & 2.3 & .8 & .7 \\
\hline 35 & -13.6 & 2.9 & 2.7 & 2.7 & .8 & .4 \\
\hline 30 & -10.3 & 2.7 & .0 & 2.2 & .8 & .2 \\
\hline
\end{tabular}


Table 9. Variance of the zonal wind component $\left(\mathrm{m}^{2} \mathrm{sec}^{-2}\right)$, Winter 1969-1974.

\begin{tabular}{lcccccc}
\hline A1t & 1 & 2 & $3^{\text {Station }}$ & 4 & 5 & 6 \\
\hline 55 & 547.6 & 479.8 & 447.3 & 339.7 & 346.5 & 197.2 \\
50 & 520.7 & 549.0 & 444.1 & 351.6 & 290.9 & 190.5 \\
45 & 414.4 & 536.4 & 502.6 & 272.5 & 215.2 & 152.3 \\
40 & 303.5 & 493.3 & 362.0 & 222.3 & 130.7 & 69.4 \\
35 & 215.7 & 371.7 & 233.1 & 139.6 & 62.9 & 49.6 \\
30 & 159.0 & 197.5 & 171.5 & 61.0 & 32.9 & 29.3 \\
\hline
\end{tabular}

Table 10. Variance of the zonal wind component $\left(\mathrm{m}^{2} \mathrm{sec}^{-2}\right)$, Spring 1969-1974.

\begin{tabular}{lcccccc}
\hline A1t & 1 & 2 & $3^{\text {Station }}$ & 4 & 5 & 6 \\
\hline 55 & 56.5 & 53.9 & 66.5 & 66.2 & 102.4 & 125.3 \\
50 & 30.7 & 55.1 & 49.3 & 57.7 & 50.1 & 70.3 \\
45 & 26.0 & 58.8 & 46.0 & 41.7 & 41.9 & 44.6 \\
40 & 14.0 & 33.4 & 31.0 & 31.4 & 29.3 & 46.7 \\
35 & 12.3 & 25.8 & 15.1 & 27.5 & 24.1 & 23.1 \\
30 & 11.0 & 18.6 & 9.6 & 12.9 & 16.4 & 13.4 \\
\hline
\end{tabular}


Table 11. Variance of the zonal wind component $\left(\mathrm{m}^{2} \mathrm{sec}^{-2}\right)$, Summer 1969-1974.

\begin{tabular}{lllllll}
\hline A1t & 1 & 2 & $3^{\text {Station }}$ & 4 & 5 & 6 \\
\hline 55 & 69.7 & 99.0 & 92.4 & 95.1 & 54.7 & 101.9 \\
50 & 42.1 & 72.2 & 65.2 & 92.1 & 55.6 & 87.3 \\
45 & 24.7 & 53.5 & 45.2 & 59.4 & 47.2 & 85.0 \\
40 & 19.1 & 24.9 & 28.0 & 32.8 & 41.6 & 62.4 \\
35 & 11.0 & 19.7 & 19.1 & 22.6 & 22.4 & 32.4 \\
30 & 7.0 & 13.7 & 14.5 & 13.5 & 11.1 & 15.0 \\
\hline
\end{tabular}

Table 12. Variance of the zonal wind component $\left(m^{2} \mathrm{sec}^{-2}\right)$, Fall 1969-1974.

\begin{tabular}{lcccccc}
\hline A1t & 1 & 2 & $3^{\text {Station }} 4^{-}$ & 5 & 6 \\
\hline 55 & 471.9 & 375.3 & 283.8 & 532.6 & 375.6 & 245.1 \\
50 & 331.7 & 384.2 & 284.3 & 521.6 & 340.3 & 223.8 \\
45 & 186.7 & 195.6 & 173.2 & 297.5 & 230.3 & 196.5 \\
40 & 165.1 & 181.7 & 179.4 & 165.5 & 123.7 & 116.5 \\
35 & 137.1 & 151.0 & 211.6 & 122.3 & 103.8 & 57.6 \\
30 & 113.7 & 88.2 & 129.2 & 69.8 & 60.9 & 44.3 \\
\hline
\end{tabular}


Table 13. Variance of the meridional wind component $\left(\mathrm{m}^{2} \mathrm{sec}^{-2}\right)$, Winter 1969-1974.

\begin{tabular}{lcccccc}
\hline \hline A1t & 1 & 2 & $3^{\text {Station }}$ & 4 & 5 & 6 \\
\hline 55 & 344.8 & 231.7 & 136.7 & 86.8 & 92.1 & 57.0 \\
50 & 361.2 & 254.0 & 134.1 & 81.5 & 61.2 & 67.2 \\
45 & 305.8 & 250.1 & 118.6 & 61.9 & 42.2 & 30.8 \\
40 & 218.0 & 182.5 & 56.8 & 46.9 & 30.1 & 17.5 \\
35 & 160.3 & 122.1 & 30.1 & 30.2 & 15.5 & 12.4 \\
30 & 127.2 & 69.1 & 11.5 & 19.6 & 11.1 & 6.0 \\
\hline
\end{tabular}

Table 14. Variance of the meridional wind component $\left(\mathrm{m}^{2} \mathrm{sec}^{-2}\right)$, Spring 1969-1974.

\begin{tabular}{lcccccc}
\hline A1t & 1 & 2 & $3^{\text {Station }}$ & 4 & 5 & 6 \\
\hline 55 & 41.9 & 39.3 & 29.2 & 34.6 & 39.2 & 63.0 \\
50 & 35.4 & 26.1 & 22.5 & 23.4 & 23.5 & 28.5 \\
45 & 22.6 & 16.9 & 14.4 & 16.7 & 18.1 & 18.2 \\
40 & 14.9 & 13.5 & 11.1 & 16.0 & 11.6 & 11.7 \\
35 & 8.1 & 6.2 & 9.0 & 9.0 & 7.8 & 10.5 \\
30 & 4.3 & 5.7 & 5.4 & 7.0 & 4.7 & 6.8 \\
\hline
\end{tabular}


Table 15. Variance of the meridional wind component $\left(\mathrm{m}^{2} \mathrm{sec}^{-2}\right)$, Summer 1969-1974.

\begin{tabular}{lcccccc}
\hline A1t & 1 & 2 & $3^{\text {Station }}$ & 4 & 5 & 6 \\
\hline 55 & 26.4 & 36.6 & 42.3 & 63.6 & 47.5 & 52.1 \\
50 & 14.2 & 23.0 & 27.5 & 33.2 & 28.5 & 31.9 \\
45 & 10.7 & 16.1 & 18.1 & 27.7 & 18.5 & 21.2 \\
40 & 4.7 & 7.5 & 11.0 & 15.2 & 10.7 & 16.5 \\
35 & 4.4 & 4.6 & 4.7 & 6.9 & 6.6 & 9.2 \\
30 & 2.6 & 3.0 & 2.8 & 4.1 & 4.3 & 6.9 \\
\hline
\end{tabular}

Table 16. Variance of the meridional wind component $\left(\mathrm{m}^{2} \mathrm{sec}^{-2}\right)$, Fall 1969-1974.

\begin{tabular}{lcccccc}
\hline Alt & 1 & 2 & $3^{\text {Station }}$ & 4 & 5 & 6 \\
\hline 55 & 337.5 & 129.3 & 128.5 & 88.8 & 92.4 & 55.7 \\
50 & 280.6 & 107.8 & 123.1 & 81.2 & 85.2 & 39.7 \\
45 & 233.0 & 67.3 & 62.9 & 60.8 & 54.9 & 36.1 \\
40 & 176.7 & 43.8 & 39.0 & 42.1 & 28.0 & 21.7 \\
35 & 146.4 & 30.7 & 29.9 & 19.1 & 17.6 & 9.7 \\
30 & 92.7 & 18.9 & 14.0 & 12.5 & 8.2 & 6.7 \\
\hline
\end{tabular}


Table 17. Eulerian integral time scale of the zonal component of turbulent velocity (day), Winter 1969-1974.

\begin{tabular}{lllllll}
\hline Alt & 1 & 2 & $3^{\text {Station }}$ & 4 & 5 & 6 \\
\hline 55 & 1.97 & - & 2.51 & 2.74 & 4.04 & .83 \\
50 & 2.22 & 3.54 & 2.98 & 2.77 & 3.78 & .94 \\
45 & 2.47 & 3.55 & 3.45 & 2.80 & 3.52 & 1.05 \\
40 & 2.73 & 3.56 & 3.91 & 2.82 & 3.26 & 1.16 \\
35 & 2.98 & 3.57 & 4.38 & 2.85 & 3.00 & 1.27 \\
30 & 3.23 & 3.58 & 4.84 & 2.88 & 2.74 & 1.38 \\
\hline
\end{tabular}

Table 18. Eulerian integral time scale of the zonal component of turbulent velocity (day), Spring 1969-1974.

\begin{tabular}{lllllll}
\hline A1t & 1 & 2 & $3^{\text {Station }}$ & 4 & 5 & 6 \\
\hline 55 & 1.01 & 1.58 & 2.26 & 1.63 & 2.79 & 1.69 \\
50 & 1.17 & 1.96 & 2.23 & 1.67 & 2.62 & 1.38 \\
45 & 1.34 & 2.33 & 2.20 & 1.70 & 2.45 & 1.07 \\
40 & 1.50 & 2.70 & 2.18 & 1.73 & 2.28 & .76 \\
35 & 1.66 & 3.08 & 2.15 & 1.77 & 2.11 & .46 \\
30 & 1.83 & 3.45 & 2.12 & 1.80 & 1.94 & .15 \\
\hline
\end{tabular}


Table 19. Eulerian integral time scale of the zonal component of turbulent velocity (day), Summer 1969-1974.

\begin{tabular}{lllllll}
\hline Alt & 1 & 2 & $3^{\text {Station }}$ & 4 & 5 & 6 \\
\hline 55 & 6.10 & - & 2.54 & 2.84 & 1.65 & 2.31 \\
50 & 5.42 & 5.37 & 3.24 & 3.51 & 3.26 & 2.17 \\
45 & 4.75 & 5.10 & 3.95 & 4.17 & 3.07 & 2.04 \\
40 & 4.07 & 4.84 & 4.65 & 4.84 & 3.77 & 1.90 \\
35 & 3.40 & 4.57 & 5.36 & 5.50 & 4.48 & 1.76 \\
30 & 2.72 & - & 6.06 & 6.16 & 5.19 & 1.62
\end{tabular}

Table 20. Eulerian integral time scale of the zonal component of turbulent velocity (day), Fall 1969-1974.

\begin{tabular}{lllllll}
\hline Alt & 1 & 2 & 3 & 4 & 5 & 6 \\
\hline 55 & 1.41 & - & 2.49 & - & 2.75 & 1.01 \\
50 & 2.11 & - & 2.68 & 6.64 & 3.25 & 1.02 \\
45 & 2.80 & 5.04 & 2.87 & 6.01 & 3.76 & 1.02 \\
40 & 3.50 & 4.03 & 3.06 & 5.39 & 4.27 & 1.03 \\
35 & 4.19 & 3.02 & 3.25 & 4.76 & 4.78 & 1.03 \\
30 & 4.88 & 2.01 & 3.44 & 4.13 & 5.28 & 1.04 \\
\hline
\end{tabular}


Table 21. Eulerian integral time scale of the meridional component of turbulent velocity (day), Winter 1969-1974.

\begin{tabular}{lllllll}
\hline Alt & 1 & 2 & $3^{\text {Station }}$ & 4 & 5 & 6 \\
\hline 55 & .39 & - & 1.91 & 1.01 & .32 & .32 \\
50 & .68 & 2.69 & 1.81 & 1.15 & .47 & .30 \\
45 & .97 & 2.81 & 1.70 & 1.28 & .62 & .28 \\
40 & 1.25 & 2.92 & 1.60 & 1.42 & .77 & .26 \\
35 & 1.54 & 3.04 & 1.50 & 1.56 & .92 & .24 \\
30 & 1.83 & 3.16 & 1.40 & 1.69 & 1.07 & .22 \\
\hline
\end{tabular}

Table 22. Eulerian integral time scale of the meridional component of turbulent velocity (day), Spring 1969-1974.

\begin{tabular}{llrrrrr}
\hline Alt & 1 & 2 & $3^{\text {Station }}$ & \multicolumn{1}{c}{4} & 5 & 6 \\
\hline 55 & .72 & .61 & .50 & 1.15 & .98 & .24 \\
50 & 1.02 & .68 & .61 & 1.00 & .89 & .24 \\
45 & 1.33 & .75 & .71 & .86 & .81 & .24 \\
40 & 1.63 & .81 & .82 & .71 & .72 & .24 \\
35 & 1.94 & .88 & .92 & .56 & .64 & .24 \\
30 & 2.24 & .95 & 1.03 & .41 & .55 & .23 \\
\hline
\end{tabular}


Table 23. Eulerian integral time scale of the meridional component of turbulent velocity (day), Surmer 1969-1974.

\begin{tabular}{llrrrrr}
\hline .15 & \multicolumn{5}{c}{ Station } \\
\hline 55 & 1 & 2 & $3^{2}$ & \multicolumn{1}{l}{4} & 5 & 6 \\
50 & .37 & .59 & .42 & 1.11 & .12 & .36 \\
45 & .43 & .61 & .43 & .99 & .23 & .34 \\
40 & .49 & .63 & .44 & .88 & .33 & .31 \\
35 & .56 & .65 & .45 & .76 & .44 & .28 \\
30 & .62 & .67 & .46 & .65 & .54 & .26 \\
& .68 & .70 & .47 & .53 & .65 & .23 \\
\hline
\end{tabular}

Table 24. EuTerian integral time scale of the meridional component of turbulent velocity (day), Fall 1969-1974.

\begin{tabular}{llllllr}
\hline A1t & 1 & 2 & $3^{\text {Station }}$ & 4 & 5 & 6 \\
\hline 55 & 1.54 & - & 1.88 & 2.40 & 1.31 & .28 \\
50 & 1.73 & 2.38 & 1.88 & 2.25 & 1.21 & .27 \\
45 & 1.92 & 2.31 & 1.89 & 2.09 & 1.10 & .26 \\
40 & 2.11 & 2.25 & 1.89 & 1.94 & .99 & .25 \\
35 & 2.31 & 2.18 & 1.89 & 1.78 & .88 & .24 \\
30 & 2.50 & 2.12 & 1.89 & 1.63 & .77 & .23 \\
\hline
\end{tabular}


Table 25. Zonal Component of Eddy Diffusivity $\left(10^{9} \mathrm{~cm}^{2} \cdot \mathrm{sec}^{-1}\right)$, Annual Average, 1969 - 1974

\begin{tabular}{lrrrrrr} 
ALT & 1 & 2 & $3^{\text {Station }}$ & 4 & 5 & 6 \\
\hline 55 & 74.3 & 59.0 & 69.0 & 63.5 & 81.2 & 40.8 \\
50 & 61.0 & 98.5 & 70.6 & 115.3 & 66.5 & 29.3 \\
45 & 61.4 & 123.6 & 98.5 & 86.2 & 80.8 & 25.9 \\
40 & 62.7 & 123.8 & 101.2 & 66.5 & 49.3 & 17.7 \\
35 & 86.5 & 149.3 & 130.5 & 72.5 & 50.0 & 13 \\
30 & 105.3 & 108.5 & 105.5 & 50.0 & 40.8 & 10.3 \\
\hline
\end{tabular}

Table 26. Meridional Component of Eddy Diffusivity $\left(10^{9} \mathrm{Cm}^{2} \cdot \mathrm{sec}^{-1}\right)$, Annual Average, 1969 - 1974

\begin{tabular}{ccccccc}
\hline ALT & 1 & 2 & $3^{\text {Station }}$ & 4 & 5 & 6 \\
\hline 55 & 15.4 & 13.3 & 13.3 & 11.1 & 6.0 & 3.2 \\
50 & 17.8 & 24.4 & 12.1 & 9.7 & 4.5 & 1.3 \\
45 & 22.6 & 32.6 & 11.6 & 8.4 & 3.7 & 1.3 \\
40 & 24.0 & 31.8 & 7.3 & 7.0 & 2.7 & .9 \\
35 & 38.3 & 36.2 & 7.3 & 6.6 & 2.6 & .7 \\
30 & 45.8 & 30.0 & 4.4 & 66.2 & 2.3 & .5 \\
\hline
\end{tabular}


Table 27. Zonal Component of Eddy Diffusivity, $\left(10^{9} \mathrm{Cm}^{2} \cdot \mathrm{sec}^{-1}\right)$, Winter 1969 - 1974

\begin{tabular}{lcccccc}
\hline ALT & 1 & 2 & $3^{\text {Station }}$ & 4 & 5 & 6 \\
\hline 55 & 112.0 & & 116.0 & 97.0 & 145.2 & 16.9 \\
50 & 119.8 & 201.3 & 137.2 & 101.0 & 114.0 & 18.5 \\
45 & 163.7 & 304.0 & 276.9 & 121.8 & 121.0 & 25.5 \\
40 & 177.9 & 377.5 & 304.7 & 135.1 & 91.6 & 17.2 \\
35 & 225.3 & 465.0 & 358.1 & 139.6 & 66.1 & 22.0 \\
30 & 249.9 & 343.5 & 262.8 & 85.5 & 43.7 & 19.6 \\
\hline
\end{tabular}

Table 28. Zonal Component of eddy diffusivity $\left(10^{9} \mathrm{~cm}^{2} \mathrm{sec}^{-1}\right)$, Spring 1969-1974

\begin{tabular}{ccccccc}
\hline ALT & 1 & 2 & $3^{\text {Station }}$ & 4 & 5 & 6 \\
\hline 55 & 16.5 & 24.6 & 43.3 & 31.2 & 82.2 & 61.2 \\
50 & 10.2 & 31.1 & 31.7 & 27.7 & 37.8 & 28.1 \\
45 & 9.6 & 39.4 & 29.2 & 20.4 & 29.6 & 13.8 \\
40 & 5.7 & 26.0 & 19.4 & 15.7 & 19.2 & 10.3 \\
35 & 5.5 & 22.8 & 9.4 & 14.0 & 14.7 & 3.0 \\
30 & 5.4 & 18.5 & 5.9 & 6.7 & 9.2 & .6 \\
\hline
\end{tabular}



Table 29. Zonal component of eddy diffusivity $\left(10^{9} \mathrm{~cm}^{2} \mathrm{sec}^{-1}\right)$,
Summer $1969-1974$

\begin{tabular}{lcccccc}
\hline A1t & 1 & 2 & $3^{\text {Station }}$ & 4 & 5 & 6 \\
\hline 55 & 122.4 & - & 67.6 & 77.9 & 26.0 & 67.8 \\
50 & 65.7 & 111.7 & 60.9 & 93.1 & 37.1 & 54.7 \\
45 & 33.8 & 78.7 & 51.4 & 71.4 & 41.6 & 49.8 \\
40 & 22.4 & 34.7 & 37.5 & 45.6 & 45.2 & 34.1 \\
35 & 10.7 & 25.9 & 29.5 & 35.8 & 28.9 & 16.4 \\
30 & 5.5 & - & 25.3 & 23.9 & 16.6 & 7.0 \\
\hline
\end{tabular}

Table 30. Zonal component of eddy diffusivity $\left(10^{9} \mathrm{~cm}^{2} \mathrm{sec}^{-1}\right)$, Fall 1969 - 1974

\begin{tabular}{lrrrrrr}
\hline A1t & \multicolumn{7}{c}{ 1 } & 2 & $3^{\text {Station }}$ & 4 & 5 & 6 \\
\hline 55 & 46.1 & - & 48.7 & - & 71.3 & 17.1 \\
50 & 48.3 & - & 52.5 & 239.3 & 76.5 & 15.7 \\
45 & 38.4 & 72.4 & 36.4 & 131.3 & 63.6 & 14.7 \\
40 & 44.9 & 56.9 & 42.6 & 69.3 & 41.0 & 9.3 \\
35 & 104.2 & 82.8 & 124.6 & 100.0 & 90.0 & 10.7 \\
30 & 159.9 & 51.1 & 127.9 & 83.1 & 92.6 & 13.3 \\
\hline
\end{tabular}


Table 31. Meridional component of eddy diffusivity $\left(10^{9} \mathrm{~cm}^{2} \cdot \mathrm{sec}^{-1}\right)$, Winter 1969 - 1974

\begin{tabular}{lrrrrrr}
\hline Alt & 1 & 2 & $3^{\text {Station }}$ & 4 & 5 & 6 \\
\hline 55 & 14.1 & - & 27.0 & 9.1 & 3.0 & 1.9 \\
50 & 25.5 & 70.9 & 25.1 & 9.9 & 3.0 & 2.1 \\
45 & 47.3 & 112.3 & 32.3 & 13.2 & 4.2 & 1.4 \\
40 & 58.9 & 114.8 & 19.6 & 15.1 & 5.0 & 1.0 \\
35 & 86.7 & 130.2 & 15.8 & 17.5 & 5.0 & 1.1 \\
30 & 113.2 & 106.1 & 7.8 & 17.4 & 5.7 & .7 \\
\hline
\end{tabular}

Table 32. Meridional component of eddy diffusivity $\left(10^{9} \mathrm{~cm}^{2} \mathrm{sec}^{-1}\right)$, Spring $1969-1974$

\begin{tabular}{ccccccc}
\hline \hline A1t & 1 & 2 & $3^{\text {Station }}$ & 4 & 5 & 6 \\
\hline 55 & 8.7 & 6.9 & 4.2 & 11.5 & 11.0 & 4.3 \\
50 & 10.4 & 5.1 & 3.9 & 6.8 & 6.0 & 1.9 \\
45 & 8.7 & 3.6 & 3.0 & 4.1 & 4.2 & 1.2 \\
40 & 7.0 & 3.2 & 2.6 & 3.3 & 2.4 & .8 \\
35 & 4.5 & 1.6 & 2.4 & 1.4 & 1.4 & .7 \\
30 & 2.7 & 1.6 & 1.6 & .8 & .7 & .5 \\
\hline
\end{tabular}


Table 33. Meridional component of eddy diffusivity $\left(10^{9} \mathrm{~cm}^{2} \mathrm{sec}^{-1}\right)$, Summer 1969 - 1974

\begin{tabular}{lrrrrrr}
\hline A1t & 1 & 2 & $3^{\text {Station }}$ & 4 & 5 & 6 \\
\hline 55 & 2.8 & 6.2 & 5.1 & 20.3 & 1.7 & 5.4 \\
50 & 1.8 & 4.0 & 3.4 & 9.5 & 1.9 & 3.1 \\
45 & 1.5 & 2.9 & 2.3 & 7.0 & 1.8 & 1.9 \\
40 & .8 & 1.4 & 1.4 & 3.3 & 1.3 & 1.3 \\
35 & .8 & .9 & .6 & 1.3 & 1.0 & .7 \\
30 & .5 & .6 & .4 & .6 & .8 & .5 \\
\hline
\end{tabular}

Table 34. Component of eddy diffusivity $\left(10^{9} \mathrm{~cm}^{2} \mathrm{sec}^{-1}\right)$, Fall 1969-
1974

\begin{tabular}{rrrrrrr}
\hline A1t & 1 & 2 & $3^{\text {Station }}$ & 4 & 5 & 6 \\
\hline 55 & 35.9 & - & 16.7 & 14.7 & 8.4 & 1.1 \\
50 & 33.6 & 17.5 & 16.0 & 12.6 & 7.1 & .7 \\
45 & 32.9 & 11.4 & 8.7 & 9.4 & 4.4 & .7 \\
40 & 29.1 & 7.7 & 5.7 & 6.3 & 2.1 & .4 \\
35 & 61.2 & 12.7 & 10.3 & 6.2 & 2.8 & .4 \\
30 & 66.7 & 11.5 & 7.6 & 5.8 & 1.8 & .4 \\
\hline
\end{tabular}


Table 35. B Values used to calculate both the zonal and meridional components of eddy diffusivity.

\begin{tabular}{|c|c|c|c|c|}
\hline$A 7 t$ & Winter & $\begin{array}{l}\text { Season } \\
\text { Spring }\end{array}$ & Summer & $\mathrm{Fa} 11$ \\
\hline 55 & .12 & .33 & .33 & .08 \\
\hline 50 & .12 & .33 & .33 & .08 \\
\hline 45 & .19 & .33 & .33 & .09 \\
\hline 40 & .25 & .33 & .33 & .09 \\
\hline 35 & .41 & .33 & .33 & .21 \\
\hline 30 & .56 & .33 & .33 & .33 \\
\hline
\end{tabular}


SUMMARY AND CONCLUSIONS

In most instances, the zonal component of eddy diffusivity is three to five times as large as its meridional counterpart. Both vary greatly with season, latitude, and altitude. Largest magnitudes are found in the vicinity of $38^{\circ} \mathrm{N}$ at $35 \mathrm{~km}$, while eddy diffusivities within the easterlies, even in regions of relatively strong flow, average one order of magnitude less. In the tropics, where seasonal variations in the wind field are much smaller, both components of eddy diffusivity remain relatively constant throughout the year. Maximum annual stratospheric values of the zonal diffusivity component occur near $40^{\circ} \mathrm{N}$ at $35 \mathrm{~km}$, while maximum annual stratospheric meridional values occur near $60^{\circ} \mathrm{N}$ at $30 \mathrm{~km}$. Both zonal and meridional diffusivity components have annual tropopausal maximums, the zonal maximum occurring at $40^{\circ} \mathrm{N}$, while the meridional maximum occurs at $50^{\circ} \mathrm{N}$. Annually, a diffusivity minimum is located between 20 and $25 \mathrm{~km}$ for both diffusivity components.

Unfortunately, dispersion rates in the region of SST travel are, therefore, rather small in comparison with the troposphere and upper stratosphere. Assuming that the vertical component of eddy diffusivity is proportional to horizontal diffusivities, convergence would be present in the lower stratosphere due to the higher vertical diffusivities above and below. Mixing between the troposphere and upper stratosphere should also be rather slow.

Striking similarities between the variance and eddy diffusivity analyses demonstrates that variations in the intensities of the turbulent fluctuations are chiefly responsible for the strong seasonal, latitudinal, and altitudinal dependence. Although wave dynamics are not we 11 understood above $30 \mathrm{~km}$, part of these fluctuations may be explained by traveling planetary waves of two-week periods found in the winter by Hirota (1968) and during summer by Meunch (1969) and Hirota (1975). Part of the greater winter variance can be attributed to stratospheric sudden warmings, both major and minor. Fluctuations on a smaller scale may be produced by interactions between vertically-propagating waves and 
strong westerly flow (Wofsy and McElroy, 1973). In any case, a better understanding of stratospheric dynamics is necessary in order to more thoroughty explain the variations in eddy diffusivity.

\section{ACKNOWLEDGMENTS}

The authors wish to thank F. J. Schmidlin for his many valuable discussions and assistance. This research is sponsored by the National Aeronautics and Space Administration, Contract NAS 6-2498. 


\section{REFERENCES}

Belmont, A. D., Dartt, D. G., and Nastrom, G. D.: Periodic variations in stratospheric zonal wind from 20 to $65 \mathrm{~km}$, at $80^{\circ} \mathrm{N}$ to $70^{\circ} \mathrm{N}$. Quart. J. Roy. Meteor. Soc., 100, 203-211, 1974.

Charney, J. G., and Drazin, P. G.: Propagation of planetary-scale disturbances from the lower into the upper atmosphere. J. Geophys. Res., 66, 83-109, 1961 .

Hay, J. S. and Pasquill, F.: Adv. Geophys. Vol. VI. Academic Press, $345 \mathrm{pp}, 1969$.

Hirota, I.: Planetary waves in the upper atmosphere in early 1966. J. Meteor. Soc. Japan, 46, 418-430, 1968.

: Spectral analysis of planetary waves in the summer stratosphere and mesosphere. J. Meteor. Soc. Japan, 53, 34-44, 1975.

Kao, S. K.: Some aspects of large-scale diffusion and turbulence in the atmosphere. Quart. J. Roy. Meteor. Soc., 91, 10-19, 1965.

, and Bullock, W. S.: Lagrangian and Eulerian correlations and energy spectra of geostrophic velocities. Quart. J. Roy. Meteor. Soc. 94, 40-62, 1964.

, and al-Gain, A. A.: Large-scale dispersion of clusters in the atmosphere. J. Atmos. Sci., 25, 214-221, 1968.

, and Powe11, D. C.: Large-scale dispersion of clusters in the atmosphere II. stratosphere. J. Atmos. Sci., 26, 734-740, 1969.

Murgatroyd, R. J.: Estimations from geostrophic trajectories of horizontal diffusivity in the mid-latitude troposphere and lower stratosphere. Quart. J. Roy. Meteor. Soc., 94, 40-62, 1969.

Meunch, H. S.: Large-scale disturbances in the summertime stratosphere. J. Atmos. Sci., 25, 1108-1115, 1968.

Newe11, R. E. et al.: The General Circulation of the Tropical Atmosphere and Interactions with Extratropical Latitudes. Vol. I, MIT Press, $252 \mathrm{pp}, 1972$.

Reed, R. J. and German, K. E.: A contribution to the problems of stratospheric diffusion by large scale mixing. Mon. Weather Rev., 93, 313-321, 1965. 
Taylor, G. I.: Diffusion by continuous movements. Proc. London Math. Soc., Ser. 2, 20, 196-211, 1921 .

Wofsy, S. C. and McElroy, M. B.: On vertical mixing in the upper stratosphere and lower mesosphere. J. Geophys. Res., 78, 2619-2624, 1973. 


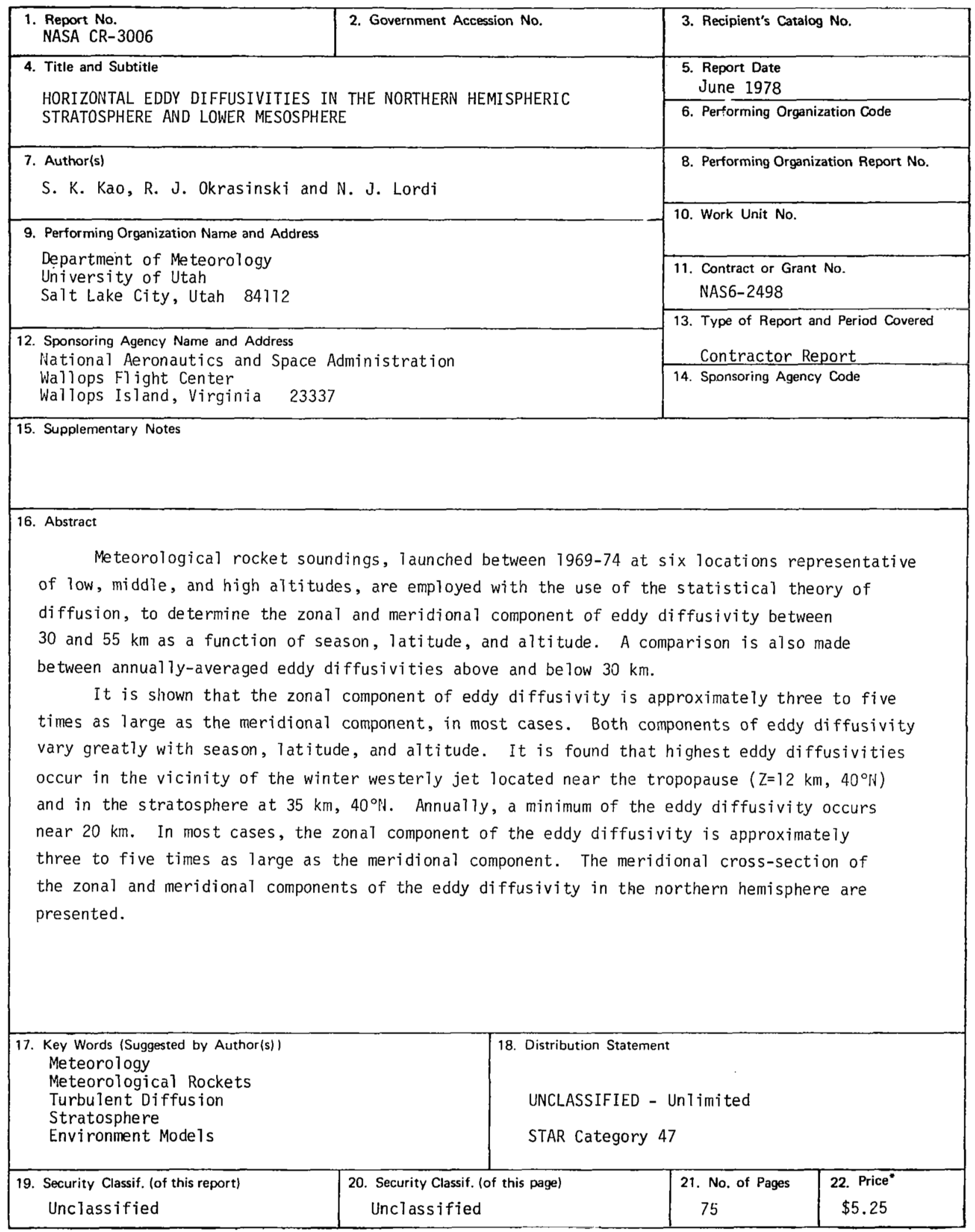

* For sale by the National Technical Information Service, Springfield, Virginia 22161 